\title{
Advancing catchment hydrology to deal with predictions under change
}

\author{
U. Ehret ${ }^{1}$, H. V. Gupta ${ }^{2}$, M. Sivapalan ${ }^{3}$, S. V. Weijs ${ }^{4}$, S. J. Schymanski ${ }^{5}$, G. Blöschl ${ }^{6}$, A. N. Gelfan ${ }^{7}$, C. Harman ${ }^{8}$,

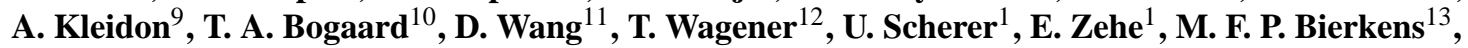 \\ G. Di Baldassarre ${ }^{14}$, J. Parajka ${ }^{6}$, L. P. H. van Beek ${ }^{13}$, A. van Griensven ${ }^{15}$, M. C. Westhoff ${ }^{1}$, and H. C. Winsemius ${ }^{16}$ \\ ${ }^{1}$ Institute of Water Resources and River Basin Management, Karlsruhe Institute of Technology - KIT, Karlsruhe, Germany \\ ${ }^{2}$ Department of Hydrology and Water Resources, The University of Arizona, Tucson, AZ, USA \\ ${ }^{3}$ Department of Civil and Environmental Engineering, Department of Geography and Geographic Information Science, \\ University of Illinois at Urbana-Champaign, Urbana, IL, USA \\ ${ }^{4}$ School of Architecture Civil and Environmental Engineering, École Polytechnique Fédérale de Lausanne - EPFL Lausanne, \\ Lausanne, Switzerland \\ ${ }^{5}$ ETH Zürich, Inst Terr Ecosyst, Soil \& Terr Environm Phys STEP, Zurich, Switzerland \\ ${ }^{6}$ Institute of Hydraulic Engineering and Water Resources Management, Vienna University of Technology, Vienna, Austria \\ ${ }^{7}$ Water Problem Institute of the Russian Academy of Sciences, Moscow, Russia \\ ${ }^{8}$ Department of Geography and Environmental Engineering, Johns Hopkins University, Baltimore, MD, USA \\ ${ }^{9}$ Max-Planck Institute for Biogeochemistry, Jena, Germany \\ ${ }^{10}$ Department of Water Management, Delft University of Technology, Delft, the Netherlands \\ ${ }^{11}$ Department of Civil, Environmental, and Construction Engineering, University of Central Florida, Orlando, FL, USA \\ ${ }^{12}$ Department of Civil Engineering, Queen's School of Engineering, University of Bristol, Bristol, UK \\ ${ }^{13}$ Department of Physical Geography, Utrecht University, Utrecht, the Netherlands \\ ${ }^{14}$ Department of Hydroinformatics and Knowledge Management, UNESCO-IHE Institute for Water Education, \\ Delft, the Netherlands \\ ${ }^{15}$ Department of Water Science and Engineering, UNESCO-IHE Institute for Water Education, Delft, the Netherlands \\ ${ }^{16}$ Deltares, Utrecht, the Netherlands
}

Correspondence to: U. Ehret (uwe.ehret@kit.edu)

Received: 16 June 2013 - Published in Hydrol. Earth Syst. Sci. Discuss.: 2 July 2013

Revised: 14 January 2014 - Accepted: 14 January 2014 - Published: 19 February 2014

\begin{abstract}
Throughout its historical development, hydrology as an earth science, but especially as a problem-centred engineering discipline has largely relied (quite successfully) on the assumption of stationarity. This includes assuming time invariance of boundary conditions such as climate, system configurations such as land use, topography and morphology, and dynamics such as flow regimes and flood recurrence at different spatio-temporal aggregation scales. The justification for this assumption was often that when compared with the temporal, spatial, or topical extent of the questions posed to hydrology, such conditions could indeed be considered stationary, and therefore the neglect of certain
\end{abstract}

long-term non-stationarities or feedback effects (even if they were known) would not introduce a large error.

However, over time two closely related phenomena emerged that have increasingly reduced the general applicability of the stationarity concept: the first is the rapid and extensive global changes in many parts of the hydrological cycle, changing formerly stationary systems to transient ones. The second is that the questions posed to hydrology have become increasingly more complex, requiring the joint consideration of increasingly more (sub-) systems and their interactions across more and longer timescales, which limits the applicability of stationarity assumptions. 
Therefore, the applicability of hydrological concepts based on stationarity has diminished at the same rate as the complexity of the hydrological problems we are confronted with and the transient nature of the hydrological systems we are dealing with has increased.

The aim of this paper is to present and discuss potentially helpful paradigms and theories that should be considered as we seek to better understand complex hydrological systems under change. For the sake of brevity we focus on catchment hydrology. We begin with a discussion of the general nature of explanation in hydrology and briefly review the history of catchment hydrology. We then propose and discuss several perspectives on catchments: as complex dynamical systems, self-organizing systems, co-evolving systems and open dissipative thermodynamic systems. We discuss the benefits of comparative hydrology and of taking an informationtheoretic view of catchments, including the flow of information from data to models to predictions.

In summary, we suggest that these perspectives deserve closer attention and that their synergistic combination can advance catchment hydrology to address questions of change.

\section{Introduction}

Introductory remark: please note that several terms used frequently throughout the paper are defined in Table A1; their first occurrence in the text is indicated by an asterisk "*”.

\subsection{Hydrology and change}

Humans and water co-exist in a tightly knit relationship: water is an indispensable resource and the basis for human life, but it also poses threats, either by excess, shortage or poor quality. As a consequence, humans have long struggled to conform natural water availability to their needs, with such prominent historical examples as the Egyptian, Greek and Roman aqueducts, the levees along the Rhine and Danube built for flood protection in the late middle ages, or the centuries-old runoff harvesting techniques used in India (Gunnell and Krishnamurthy, 2003). From practical questions of how to ensure water availability and protection, hydrology developed into a problem-centred or engineering discipline, providing tools for design flood estimation, flood forecasting, and estimation of water availability, etc.

Meanwhile, being one of the most prominent closed loop processes on our planet, the water cycle has also sparked considerable scientific interest, as it plays a major role in global energy and mass cycling (Kleidon, 2010) and connects, like no other, the abiotic environment with the bio- and anthropospheres, thereby governing the distribution of life on the planet. This interest led to hydrology developing into a scientific discipline in its own right, with aims to understand, analyse and describe the phenomena, structures, and processes of the global water cycle.
The dual foci of hydrology, one on solving practical water-related problems, the other on generating scientific insight, along with the multitude of questions, domains and spatiotemporal scales of interest, has led to a diversity of paradigms*, scientific theories*, scientific laws*, and approaches. What unites many of these, however, is an underlying assumption of "stationarity"* in regards to many of the boundary conditions and system properties (e.g. stationarity of climate, flow regimes, ecosystem function, catchment and river morphology, etc.). While this assumption has, to date, been helpful in simplifying the search for solutions to many hydrological problems, its general applicability is increasingly doubtful due to two main reasons: (i) the tendency of components of hydrological systems to shift from stationary to non-stationary behaviour and (ii) the questions posed to hydrology have become increasingly complex. These require us to consider the interactions of increasingly larger numbers of subsystems and to extend the temporal extent of predictions. With respect to the former, humans themselves are the major causes of change (Wagener et al., 2010), with the most prominent examples being their influence on global climate and land use, which we will briefly discuss in the following.

There is, now, very little doubt that humans play an important role in global warming and the related changes to global climate (Oreskes, 2004; IPCC, 2007), thereby triggering a chain of changes that propagate throughout the water cycle. To name just a few: (i) shifts in atmospheric circulation patterns affect the annual and seasonal characteristics of rainfall (Bárdossy and Caspary, 1990), (ii) glacial retreat due to global warming affects river flow regimes (Huss, 2011), (iii) increasing water temperature in lakes alters the regimes of thermal layering and aeration (and hence water quality) and favours the invasion of new species (Werner and Mörtl, 2004), and (iv) rainfall regimes at the regional scale are influenced by human strategies for rainfall enhancement (Griffith et al., 2009).

Comparable in impact to the changes in global climate, man-made changes in land use affect all aspects of the water cycle around the world, which in turn alter weather and climate from local to regional scales. Altogether, croplands and pastures have supplanted natural vegetation to become one of the largest terrestrial biomes on the planet, now occupying $40 \%$ of the land surface (Foley et al., 2005), and an estimated $60 \%$ of present soil erosion yields are induced by human activity (Yang et al., 2003). Arguably the most dramatic example of human influence on regional hydrology is the Aral Sea, where withdrawals of water (for irrigation) from the 1.5 million $\mathrm{km}^{2}$ basin have led to a massive shrinkage and desiccation of the lake, extinction of the aquatic ecosystem, and reduction of regional rainfall to one-third of its initial value and lake inflow to one-sixth (Gaybullaev et al., 2012). Another interesting example is the fact that $55 \%$ of Dutch land would be under water if it were not for the dykes built by man (IPCC, 2007; Corrigendum to IPCC, 2013). Last, but not least, urbanization has had a major effect on local and 
regional regimes of water and sediment flows and on fluvial morphology (Hawley and Bledsoe, 2011), with the consequence that aquatic life cycles, habitats and food webs have been altered (Poff et al., 2006).

To summarize, the hydrological cycle is increasingly affected by changes, many of them triggered by humans, which extend from the local to global scales, act on short to decadal timescales, affect all characteristics of water-related dynamics (mean, variability, extremes), and extend over the atmosphere, critical zone (boundary layer), groundwater, lakes, rivers and oceans.

\subsection{Hydrological complexity and co-evolution}

Taking the perspective of systems theory, hydrology deals with an overwhelmingly complex, non-linear coupled system, with feedbacks that operate at multiple spatiotemporal scales (Kumar, 2007; Sivakumar, 2009). The fact that aspects of the hydrological system have been successfully dealt with in greatly simplified ways (through isolated treatment of sub-systems and linearized approximation of dynamics), while neglecting many of the feedbacks, is made possible mainly by the fact that long-term co-evolution* of the various system components (morphology, vegetation, river networks, etc.; see Corenblit et al., 2011) has resulted in stable system configurations, wherein stabilizing negative feedback effects govern the system dynamics, so that the system degrees of freedom are greatly reduced.

For such systems, the net effect of the past interplay of feedbacks has become engraved in the system configuration, so that many of the system-shaping feedback processes need not be explicitly included in a representation of system dynamics. However, when such systems are forced sufficiently far from these stable steady states*, either by changing the boundary conditions or system properties, system reconfigurations towards new, unexpected and potentially unpredictable transient* and stable states may be triggered (Phillips, 1993, 2006). As the nature of the new system configurations will be largely governed by the interplay of positive and negative feedbacks, limits to the applicability of hydrologic solutions based in the stationarity assumption quickly become obvious.

\subsection{Goals and scope of this paper}

The need to move beyond a dependence on the "stationarity assumption" therefore poses a grand challenge to hydrology, which has recently been acknowledged (among other initiatives) by the IAHS, devoting the decade 2013-2022 "Panta Rhei" (Montanari et al., 2013) to "predictions under change", PUC (Sivapalan, 2011; Thompson et al., 2013). Therefore, in the context of this IAHS initiative, the main aim of this paper is to present and discuss paradigms and scientific theories which we believe will be helpful in advancing hydrology towards understanding and predicting the behaviour of hydrological systems under change.

To be clear, this paper is intended to serve primarily as an overview, while many of the topics we identify are dealt with in greater detail within this special issue; we will point to them where appropriate.

PUC questions pose both a challenge and an opportunity for the science and practice of hydrology. Because of the increasing need to jointly consider hydrological system components with processes from the abiotic environment, and the bio- and the anthroposphere across many scales, we are afforded the opportunity to begin a unification of the still fragmented landscape of hydrological theories and approaches into a more comprehensive framework. The second aim of this paper, therefore, is to discuss the structure and components of such a framework and to examine what role each of the paradigms presented may play within it.

For the sake of focus, we will limit the paper to the topic of "catchments", these being the most important and intuitive conceptual hydrological construct, although many of the paradigms presented here will also be applicable to other hydrological sub-systems (e.g. groundwater) and to the global hydrologic cycle.

The remainder of the paper is structured as follows: we begin with some general definitions and an overview of the nature of explanation in hydrology (Sect. 2). Then we present a historical perspective on the development of hydrology, discuss where it stands today and consider whether the methods it offers are suited for questions dealing with PUC (Sect. 3). In Sect. 4, we discuss a number of paradigms and theories that we believe will be helpful for understanding the nature of catchments under change; these include the theory of complex dynamical systems (Sect. 4.1), catchment selforganization, co-evolution and similarity (Sect. 4.2), thermodynamics (Sect. 4.3) and information theory (Sect. 4.4). In Sect. 5, we summarize and conclude with a discussion of how the various paradigms presented here may contribute to the development of a general framework for the science of hydrology.

\section{The nature of explanation in hydrology}

\subsection{Which scientific approaches and methods do hydrologists use to describe, explain and predict hydrological phenomena and why?}

In this section, we will discuss the general ways of explanation used in hydrology. This provides the ground upon which to discuss how problems associated with hydrological change can be approached, and to identify which currently available methods may be potentially useful for addressing them.

It is important, first, to recognize that "explanation" in hydrology is characterized by a considerable degree of 
pluralism, as it does also within the earth sciences in general (this paragraph largely draws from Kleinhans et al., 2005). This pluralism stems from different types of explanation, and the interdisciplinary and underdetermined nature of hydrology, as we will discuss below. In general, we can distinguish three co-existing types of explanation:

1. Descriptive actual-sequence explanations of the course of (unobservable) sequences of past events such as soil genesis (Buol et al., 2011), palaeoflood reconstruction (Baker, 1987), long-term reconstruction of fluvial morphology (Garcia-Garcia et al., 2013) or land use and climate (Ropke et al., 2011).

2. Robust-process explanations that provide cause-andeffect relations without going into detail (typically, they are referred to as general mechanisms or process patterns). A typical example from hydrology is the description of the general mechanisms of surface runoff production. Such explanation can be formulated without full knowledge of initial and boundary conditions.

3. Causal explanations in the form of scientific laws that provide a detailed description of (typically isolated) mechanisms and the exact ranges of applicability, in which they must qualify as exception free and irreducible (e.g. Darcy's law for saturated flow in porous media).

In addition to this, further pluralism arises from the diversity of questions that hydrologic investigations deal with, and from the occurrence of emergent phenomena (see Sect. 4.2.1). These multiple perspectives have, historically, favoured the formulation of laws that apply to specific phenomena and at particular spatio-temporal scales. Going further still, and due to its interdisciplinary nature, explanation in hydrology has also embraced concepts from a variety of disciplines including physics, chemistry, biology, geology, ecology and systems theory, and increasingly relies on quantitative computer models (Oreskes, 2003; Winsberg, 2010) for analysis, explanation, forecast*, prediction* and projection*, despite their many limitations (Oreskes et al., 1994; Winsberg, 2010).

This high degree of explanatory pluralism in hydrology is, we believe, an obstacle to the further development of the science, as it hampers communication and cooperation among its sub-disciplines. However, the main reason for its existence, that being "underdetermination", is likely to be difficult to overcome. Here, the term underdetermination is used for "the lack of sufficient data to formulate (and test) complete causal explanations, caused by the impossibility of complete observation (e.g. in the subsurface or due to long process timescales) and of undisturbed observation". This situation is, of course, complicated by the fact that many hydrological systems exhibit strongly nonlinear behaviour and have unknown boundary and initial conditions. Together, this imposes principal limits on our ability to make (deterministic) predictions (Koutsoyiannis, 2010). So the important question that arises is

\subsection{How can we cope with underdetermination and reduce explanatory pluralism in hydrology?}

This has been a longstanding issue, but it has now become even more relevant when faced with the need to address questions of hydrological change. When systems are changing, we can be quickly confronted with a diminished ability to predict the future based purely on past observations, due to the potential invalidation of steady-state* laws.

From a methodological point of view, one useful approach to diminishing the problem of underdetermination is to attempt to combine knowledge contained in actual-sequence and robust-process explanations with laws in a hierarchical way (i.e. locally valid laws can be tested to establish robustprocess predictions on a larger scale, and robust-process explanations can be tested against long-term developments of the system). In this paper, such an approach is reflected in our suggestion to view catchments both as (i) systems of many component sub-systems that self-organize on the basis of locally valid laws (Sect. 4.2.1) and (ii) as co-evolving entities (Sect. 4.2.2). We suggest that a key to explaining selforganization and emergence is to treat catchments as open dissipative thermodynamic systems (Sect. 4.3), which can thereby provide a hierarchical framework in which sectoral laws based on emergent phenomena can be placed. It is also a framework in which limits to the intensity of processes can be formulated.

While considering the above suggestions, it is perhaps helpful to recognize that algorithmic information theory (AIT), offers a complementary (albeit more idealized and philosophical) view of the nature of explanation, data, models and laws. AIT is based on the perspective that all data, models and laws can, in principle, be represented as algorithms on some universal elementary computer (Solomonoff, 1964; Chaitin, 1966; Kolmogorov, 1968). When approached from this point of view, an "explanation" is simply a useful form of "data compression" which enables a description of some aspect of the system in a much shorter form (requiring less storage), and a "theory" or "law" is a useful "computer program" that is capable of generating the observed data as output (Weijs et al., 2013a, b). If a theory is able to represent the nature of the structure* in some observed data, then the computer program representing it (the new description) should require less storage than the original data (original description). This quantifies the principle of parsimony by means of information measures. The main implication of this framework is that the "why" questions of science are, at a fundamental level, really secondary to the "how" questions, since any explanation of an observed phenomenon ("why") consists of a description ("how") at a deeper level (Feynman, 
1965). A more detailed treatment of (A)IT is presented in Sect. 4.4.

In this context, it is also useful to realize that AIT, as an extension of information theory (IT), is closely linked to Bayesian probability and the classical information theory of Shannon (1948). What makes these attractive as a basis for scientific investigation is that they offer a general framework for the evaluation of information content (expressed in terms of change in uncertainty about a target quantity of interest), across data, laws, and models. Importantly, this reminds us that the information content of any data, law or model depends critically on the question being asked and on the nature of the prior knowledge available. Accordingly, the best current explanation necessarily depends on the information currently available. These insights are particularly important to the investigation of hydrological phenomena, where underdetermination leads to a strong reliance on computer-based models as strong priors in hypothesis testing, analysis and prediction across scales.

\section{Catchments and catchment hydrology}

The existence of catchments is the blessing and curse of hydrology and it has had a major impact on its historical development. To illustrate this, we will discuss what a catchment is, sketch the historical development of the science of catchment hydrology and, from this, take a look into its future.

\subsection{What is a catchment - characteristics and peculiarities}

The predominant feature of a catchment is its convergence into a stream channel. This allows the total outgoing flux of surface runoff to be readily measured, which, in turn, allows straightforward closure of the catchment water mass balance. This water balance equation has so far proven to be the most useful physical principle in hydrologic analysis, and it greatly facilitates the estimation of harder-to-observe fluxes such as evapotranspiration. The second interesting characteristic of a catchment is that the processes associated with landscape and soil formation operate at much longer timescales than do rainfall, evapotranspiration and the shallow water flow that contributes to most of the runoff (e.g. Skøien et al., 2003). Similarly, changes in land use typically occur relatively slowly as do changes in stream morphology. This allows a treatment of catchment dynamics in which slow and fast timescales are separated (Blöschl and Sivapalan, 1995), thereby transforming a complex problem into two simpler ones, and avoiding the explicit representation of feedbacks between system states (e.g. soil moisture) and catchment structure (e.g. topography) (Gaál et al., 2012). For example, in hydrological modelling, it is often conveniently assumed that the variables representing climate vary in time while the general model structure and the model parameters representing catchment characteristics remain time-invariant (Merz et al., 2011; Blöschl and Montanari, 2010).

An interesting consequence of this separation of timescales is that hydrological models have, historically, been "tuned" to remove bias via calibration (Gupta et al., 1998, 2008; Blöschl et al., 2013). The ability to separate slow and fast timescales can also be found in other disciplines such as meteorology, where short timescales are associated with atmospheric motion and long scales with, for example, ocean and ice dynamics (Hasselmann, 1976). However, a key point is that if the spatio-temporal scales of interest are close to those of structure formation and decay, then more constraints, such as the mass- energy- and momentum balances are required to allow solution of the dynamical system equations. A typical example from meteorology is local weather forecasting including the formation of local convective structures. In catchment hydrology, timescales of interest are typically such that a separation of scales, and with it a simplified treatment of dynamics, is possible.

\subsection{The historical development of catchment hydrology research}

The characteristics of catchments discussed above have been a strong motivation for hydrologists to look at hydrological processes from a catchment perspective. Equally important, many societal problems that hydrologists have had to solve occur at the catchment scale, giving additional impetus for a catchment scale perspective. Indeed, when looking back in history, it is clear that the evolution of hydrology has been mainly driven by the societal problems of water management and risk (Nash et al., 1990; Eagleson, 1991). As hydrology is a broad discipline, we will discuss its historical evolution only from the viewpoint of flood modelling, which is of interest both from a theoretical and practical perspective.

The first approaches to model the dynamics of runoff generation and routing, such as the rational method (Mulvany, 1850) and the unit hydrograph concept (Sherman, 1932; Dooge, 1973) mainly adopted assumptions of linearity and time invariance, and were developed at the event scale, lumped over the catchment. Early in the 20th century, questions of agricultural management led to the integration of soil moisture dynamics into models, thus introducing the first major representation of interactions/feedbacks (between evaporation, soil moisture and runoff) and the gradual move towards higher temporal resolution, eventually resulting in catchment scale lumped models such as the Stanford watershed model (Crawford and Linsley, 1966), the Sacramento model (Burnash et al., 1973) and the HBV model (Bergström, 1976). Meanwhile, quite isolated from these developments and motivated mainly by flood frequency analysis, flood hydrology also developed a strong statistical branch (Kritsky and Menkel, 1946; Gumbel, 1941; Merz and Blöschl, 2008). 
This was soon followed by models with increasing spatial resolution (see the blueprint of Freeze and Harlan, 1969), based on local-scale equations (e.g. SHE, Abbott et al., 1986), and making use of the growing knowledge on hydrological processes and availability of spatially highly resolved data. Today, the development continues towards increasingly complex water balance models involving vegetation dynamics (e.g. LARSIM, Ludwig and Bremicker, 2006) or SVAT models in the context of climate modelling (e.g. CLM, Dai et al., 2003), with increasing representation of within-catchment feedbacks and land-atmosphere interactions. Over the decades, discussions have taken place on (i) how to obtain estimates for the model parameters of these kinds of models given the complexity of the processes in the landscape (Gupta et al., 1999; Hogue et al., 2006; Rosolem et al., 2013) and (ii) whether the assumed model structures are appropriate in the first place (Beven, 1989; Grayson et al., 1992; Abramowitz et al., 2006, 2007). Much of the difficulty is related to scale issues, the fact that laboratory equations cannot be straightforwardly extended to the catchment scale, and the difficulty with measuring model parameters in the field at the appropriate scale (Blöschl and Sivapalan, 1995). Advances in measurement techniques, in particular about spatial patterns (e.g. Grayson et al., 2002), helped address the dispute by obtaining spatial estimates of model parameters, validating hydrological models in terms of their spatial predictions, and assessing the effect of the spatial structure (or organization) of hydrological characteristics within the catchment on model output and model uncertainty. Examples for information on spatial patterns include soil moisture (Western et al., 2001), snow (Blöschl et al., 1991) and stream water temperatures (Westhoff et al., 2011). The discussion on what scale best to formulate hydrological processes, however, has not been resolved.

On the whole, the existence of catchments has been a blessing for hydrology, by enabling the development of relatively simple but successful models based on the assumptions of stationarity, linearity concepts and the availability of very few observations. On the other hand, this has also slowed the development of models that properly represent the true complexity of water-related processes along the hydrological cycle and that simulate the interplay of short- and long-term dynamics.

However, it is the latter kind that is increasingly required to deal with catchments under change, wherein the assumption of stationarity (or more generally the assumption of separation of timescales) must be relaxed. In the next section, we will examine several perspectives on catchments that will potentially be useful to direct the further development of hydrological models to approach such questions of change.

\section{Perspectives on catchments under change}

\subsection{Catchments as complex dynamical systems}

The first perspective we take is that of catchments as complex dynamical systems. The theory of dynamical systems has since its beginnings in the 1950s (Forrester, 1968), developed into a well-established branch of science, that has been proven useful across a wide range of problems and systems (Strogatz, 1994), ranging from weather prediction (Lorenz, 1969), ecology (Hastings et al., 1993; Bossel, 1986) and hydrology (Koutsoyiannis, 2006) to geomorphology (Phillips, 1993) and coupled human-ecological systems (Bossel, 1999, 2007) among many others. The steps of dynamical system analysis (DSA) include identification of the system structure (border, components, and state variables) and of the laws governing its dynamics (i.e. the evolution* of system states over time). A major strength of DSA is that it offers a method for system classification based on its degrees of freedom (state variables) and the nature of its dynamics (linear, non-linear, chaotic, see Table 1), which allows conclusions to be made on system stability and predictability.

Although there is, to date, no consensus regarding an exact definition of what characteristics define the special class of complex dynamical systems, several constituent features are generally accepted (Heylighen, 2008; Sibani and Jensen, 2013). These include strongly nonlinear and possibly chaotic behaviour, resulting from the combinatorial effects of damping/amplifying feedbacks and interactions between sub-systems, the occurrence of emergent behaviour, limited predictability and the potential for self-organization in Ashby's terms (Ashby, 1962; see also Sect. 4.2.1). Accordingly, catchments qualify as complex dynamical systems: hydrological processes exhibit nonlinearity over a wide range of spatio-temporal scales, from micro-scale fingering in soil water infiltration (Ritsema et al., 1998) to the Hurst-Kolmogorov behaviour of hydrological processes on the climatic scale (Montanari et al., 1997; Koutsoyiannis et al., 2009), which can lead to high sensitivity to initial and boundary conditions and potentially to chaotic behaviour (Sivakumar, 2000). In addition, catchments exhibit emergent behaviour (see Sect. 4.2.1), changing patterns of stable and unstable states (Dooge, 1986; Brandes et al., 1998; Zehe et al., 2007), complexity of sub-system behaviour at different scales (Zehe and Blöschl, 2004; Rodriguez-Iturbe et al., 1991) and varying sub-system memory (e.g. residence times in rivers typically of the order of days, whereas in groundwater systems it may be decades).

More specifically, according to the definitions of Weinberg (1975), hydrological systems are often systems of intermediate complexity and organization (Dooge, 1986). Existing between the realms of organized simplicity (mechanisms) on the one hand and unorganized complexity (aggregates) on the other implies that hydrological systems can neither be fully described and predicted by methods of 
Table 1. Classification of dynamical systems (simplified from Strogatz, 1994, p. 10, Fig. 1.3.1).

\begin{tabular}{|c|c|c|c|c|c|}
\hline & \multicolumn{5}{|c|}{ Number of variables } \\
\hline & $n=1$ & $n=2$ & $n \geq 3$ & $n \gg 1$ & Continuum \\
\hline \multirow[t]{2}{*}{ Linear } & Growth and decay & Oscillations & & Collective phenomena & Waves and patterns \\
\hline & Radioactive decay & Two-body problem & & $\begin{array}{l}\text { Solid-state physics } \\
\text { Equilibrium statistical mechanics }\end{array}$ & $\begin{array}{l}\text { Heat and diffusion } \\
\text { Viscous fluids }\end{array}$ \\
\hline \multirow[t]{5}{*}{ Nonlinear } & & & Chaos & \multicolumn{2}{|c|}{ Spatio-temporal complexity } \\
\hline & Fixed points & Pendulum & Strange attractors & Lasers & Nonlinear waves \\
\hline & Bifurcations & $\begin{array}{l}\text { Anharmonic } \\
\text { oscillators }\end{array}$ & Three-body problem & $\begin{array}{l}\text { Non-equilibrium } \\
\text { statistical mechanics }\end{array}$ & $\begin{array}{l}\text { Turbulent fluids } \\
\text { (Navier-Stokes) }\end{array}$ \\
\hline & $\begin{array}{l}\text { Overdamped system } \\
\text { logistic equations }\end{array}$ & Predator-prey cycles & $\begin{array}{l}\text { Fractals } \\
\text { Forced nonlinear } \\
\text { oscillation }\end{array}$ & $\begin{array}{l}\text { Nonlinear solid-state } \\
\text { physics }\end{array}$ & $\begin{array}{l}\text { Reaction-diffusion, } \\
\text { biological and } \\
\text { chemical waves }\end{array}$ \\
\hline & & & & Ecosystems & \\
\hline
\end{tabular}

deterministic mechanics (as for mechanisms) nor by statistical physics (as for aggregates). Hydrological systems, as systems of "organized complexity", exhibit a mixture of both dimensions, being roughly predictable under some conditions and at certain scales but unpredictable at others. Waldrop (1992) termed such systems as being at the "edge of chaos". In this context, DSA may prove useful for hydrology science by providing the tools (Strogatz, 1994) for constructing a required "concept of reality intermediate between determinism and randomness in which changing patterns of stability and instability contribute to the self-organization of systems" (Dooge, 1986).

In the context of PUC questions, an important potential of DSA lies in providing a method for classifying hydrological systems with respect to their predictability and, therefore, for distinguishing between predictable and unpredictable systems (one of the "key unresolved issues and research challenges in hydrology"; Blöschl, 2006). A number of studies have been carried out in this context, including (i) identification of patterns of hydrologic predictability (Zehe and Blöschl, 2004; Zehe et al., 2007), (ii) analysis of predictability limits caused by dynamic changes in spatial catchment complexity (Kumar, 2011) and (iii) defining factors affecting global hydrologic predictability (Shukla et al., 2013). Further, DSA can contribute to the identification of patterns of long-term predictability in regional water cycle processes, through division of the system into components of different memory length (Demchenko and Kislov, 2010) similar to approaches used in climate prediction (Hasselmann, 1976). DSA can also be useful for analysing projected scenarios of hydrological change. Conditions can be analysed, and physical mechanisms detected, which lead to instability of hydrological systems, induction of new stable states, and conversion of former time-invariant structures into timevariable ones, etc. In particular, dynamical invariants (known as the Lyapunov exponents) related to the average rates of divergence or convergence of trajectories in phase space, can be used to quantify the effects of instability, and can thereby serve as measures of stability, resilience, and ultimately predictability of hydrological systems under change.

In the context of addressing PUC questions, some limitations of classical DSA are its traditional focus on systems having time-variable states but time-invariant structure. From a thermodynamic perspective, catchments are open, dissipative, and far from equilibrium, and can experience substantial changes in structure (either build-up or decay, see also Sect. 4.3). Further, DSA does not, by itself, provide answers about whether principles exist that direct the development of catchment structure. Pathways to address these issues will be discussed in Sects. 4.2 and 4.3. Finally, caution should be exerted when estimating the degrees of freedom of a hydrological system. Deriving this number from its number of dependent variables may result in an overestimation, as it may in reality be much smaller due the synchronizing effect of emergence at various scales, (see also Sect. 4.2.1).

To conclude with the words of Dooge (1986), "Generally, systems theory attempts to produce laws that provide insight rather than specific answers". In accordance with this, we believe that it is these insights that form the potential of DSA for hydrologic science in the context of PUC questions.

\subsection{Catchments as self-organizing, co-evolving systems}

In this section we discuss why, despite the dazzling array of hydrological processes acting at various scales and across many compartments, catchments do not behave as random conglomerates, but instead exhibit a high degree of organization and structure. In fact it is not despite, but rather because of the large number of sub-systems and processes that self-organization and emergence can take place (see Sect. 4.2.1) and that the interaction of catchment components over time (i.e. co-evolution in the sense of a joint, non-random development) eventually leads to harmonized 
sets of constituents (see Sect. 4.2.2) that are likely to occur repeatedly given similar initial and boundary conditions. By taking the view of catchments as self-organizing, co-evolving systems and by exploiting catchment similarities to transfer information across space or time (Sect. 4.2.3), it becomes possible to constrain the range of future trajectories of the evolution of a catchment, thereby enabling predictability under change.

\subsubsection{Catchments as self-organizing systems}

The organization of light waves into coherent laser light, a bowed string emitting sound waves of only a single key and its harmonics, establishment of predator-prey cycles in ecology, and the formation of eddies in fluid flow are all examples of a phenomenon that is ubiquitous in nature - the ability of systems to spontaneously develop macro-scale (macro-scale here refers to a scale similar to the extent of the system) properties or structures (spatial, temporal or functional) from the cooperation of its micro-scale (i.e. much smaller than the extent of the system) constituents (i.e. for the system to become more than the simple sum of its parts). This is fundamentally different from macro-scale properties that simply arise from superposition of the properties of a set of micro-scale constituents (e.g. total mass of a system as the sum of subsystem mass or the linear macro-scale function of a system composed of linear sub-systems). The appearance of such macro-scale structure and hence the establishment of a hierarchy within the system is referred to as emergence, the underlying process self-organization (Jetschke, 2009). In this context, "organization" can be thought of as a process leading to conditionality, i.e. the dependence of the value or state of an entity on the state or value of another (Ashby, 1962). Altogether, the notion of self-organization is reminiscent of Darwins concept of evolution (Haken, 1980).

Within the scientific field of synergetics, which is closely related to the theory of complex dynamical systems (see Sect. 4.1) and thermodynamics (see Sect. 4.3), several criteria for the occurrence of emergence have been established (e.g. Haken, 1980). In particular, the system is typically composed of many similar, interacting sub-systems that are subject to external influences. Further, the nature of their interactions can usually be described by a few macro-scale order parameters, which are in turn dependent on external conditions. Depending mainly on the values of these order parameters, the nature of the interactions change (often in an abrupt, threshold-like manner, and caused by a shift from none or negative towards positive feedback effects among the subsystems) from non-cooperative (non-conditional) to cooperative (conditional) behaviour. Importantly, for an emergent macroscopic property/structure to arise, the temporal persistence of the order parameters must be much larger than the timescale of the cooperative processes. Also, states that are far from thermodynamic equilibrium* are favoured for selforganization to occur (see Sect. 4.3).
There are many striking examples of emergence along the hydrological cycle: flow fingering (Hill and Parlange, 1972) leads to structured flow at the macro-scale (soil columns), its occurrence being governed by the relationship between soil moisture and the hydraulic properties of soil and fluid. This cooperative effect is caused by a positive feedback between soil moisture and hydraulic conductivity. Similarly, the formation of persistent preferential flow structures in a catchment (e.g. river networks visible at the macro-scale) is governed by just a few order parameters (the degree of convergence of initial geopotential gradients, and the relationship between fluid shear stress and resistance to soil erosion), but adds an entirely new function to the system. In this case, the conditional (positive feedback) mechanism is related to the locally steepened gradients (towards the channel) and the reduced flow resistance (in the channel) (see also Kleidon et al., 2013). Note that the formation of hillslope subsurface storm flow (see Fig. 1 in Troch et al., 2009 or Lehmann et al., 2007) and other kinds of threshold-like behaviour (Ali et al., 2013; Zehe and Sivapalan, 2009) can also be seen as resulting from a hierarchy of emergent phenomena.

From the above discussion, it should be clear that hydrologists (and scientists in general) have long taken advantage of emergent phenomena when formulating laws for macroscale dynamics in systems composed of many sub-systems (with the definition of the macro-scale being dependent on the specific purpose). However, for hydrological systems that can be viewed as exceedingly complex, and where one has to deal with predictions under change, there still lies considerable potential in the synergetic view. Although it is likely that we will never be able to fully describe such systems in terms of their smallest component entities (in a reductionist sense), a strategy based on making use of emergent phenomena can greatly reduce the degrees of freedom to a manageable number of order parameters, thereby making prediction a more straightforward (and less uncertain) task. It should be noted, however, that while self-organization typically leads to macroscopically stable (and hence predictably steady) states, such systems can also exhibit complex (even chaotic) dynamics under certain conditions of their order parameters.

The general findings of synergetics have been found to be applicable to a wide range of systems, from physical and chemical to biological and social. As hydrological systems can comprise components from all of these, working within a common framework and language of synergetics has the potential to simplify the transfer of knowledge and improve communication. Further, the fact that self-organization constrains the degrees of freedom for a catchment to develop is also a reason for the apparent similarity of many catchments (see Sect. 4.2.3). However, despite the potential of exploiting self-organization, there are many challenges and limitations that should not be ignored; for example, the macro-scale order parameters and their corresponding macro-scale laws must be identified, the ability to make meaningful statements 


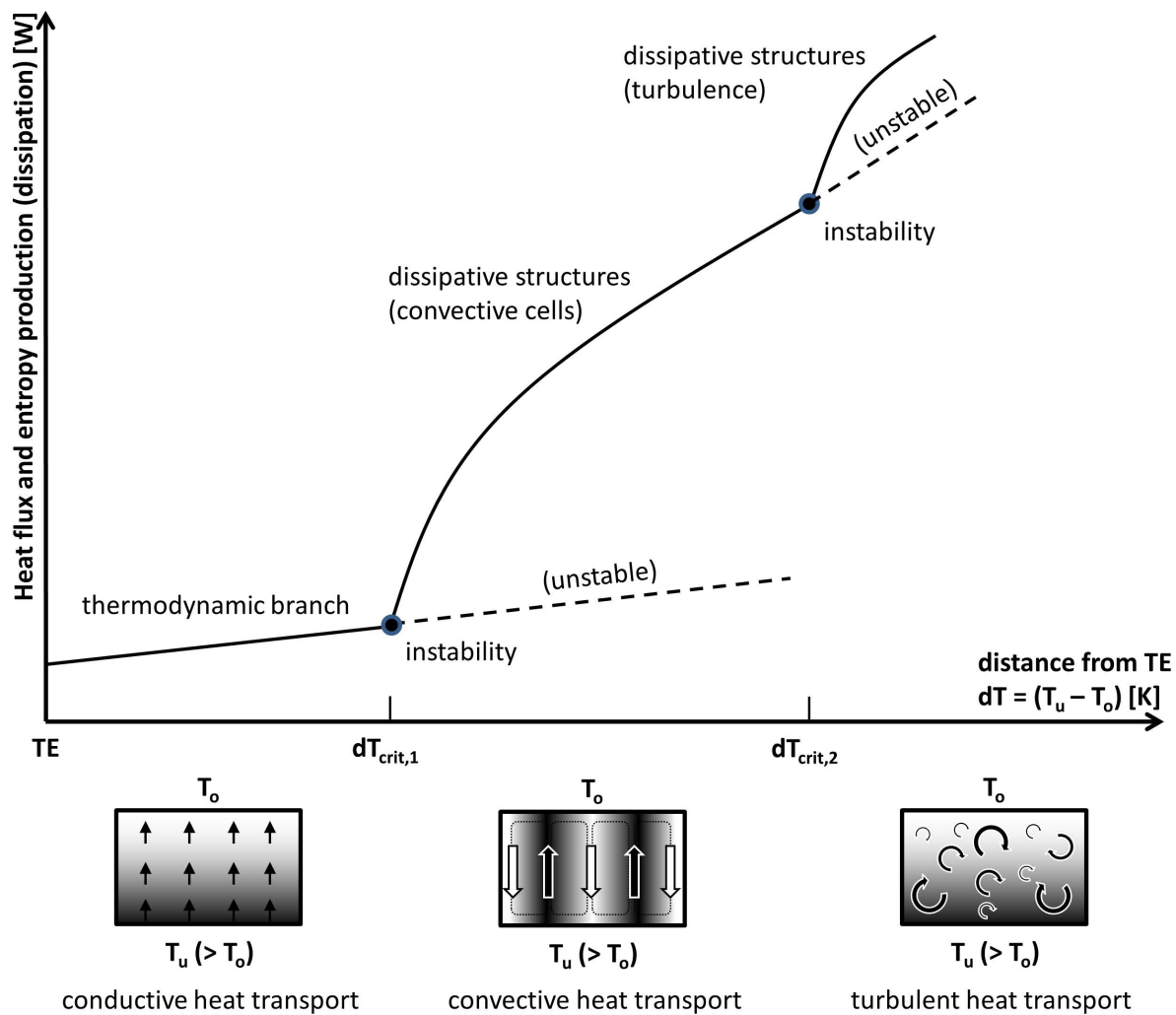

Fig. 1. Highly simplified sketch of steady-state heat transport and entropy production (dissipation) in a reservoir heated at the bottom, as a function of distance from thermodynamic equilibrium (TE). The distance from TE is expressed by the temperature difference between bottom and top. Beyond a critical distance from TE, self-organization creates macroscopic structure (convective cells, turbulence), accelerating the heat flux from bottom to top.

about detailed behaviours at the micro-scale is lost, and the effects of self-organization can only be exploited under the assumption that the system does not change at the microscale. The latter may not always be true, especially for catchments under change. If for example the micro-scale soil hydraulic properties in a catchment change due to external influences, previously visible fingering may cease to occur.

\subsubsection{Catchments as co-evolving systems}

The hydrologic system embedded in a catchment is both a driver and a result of changes in soil, topography, biota and human actions over multiple timescales of history, resulting in striking and remarkable patterns at all spatial scales, as described in the previous section. Recent advances in geomorphology, pedology and ecology have begun to unravel the pathways and mechanisms that have determined these patterns of topography, soils and species in individual landscapes. They do so by asking a different type of question about the landscape to that posed by a hydrologic model - rather than trying to predict the behaviour of an individual place in terms of its current properties, they seek explanations for the variations in structure and function between places in terms of the mechanisms that have dominated their co-evolution (Harman and Troch, 2014).

This approach has been called "Darwinian" to contrast it with "Newtonian" efforts aimed at prediction of individual catchments based on physical laws (Sivapalan et al., 2011; Harman and Troch, 2014; Wagener et al., 2013). Charles Darwin's own profound insights can be traced to his focus on the relationship between individuals and populations, rather than either alone, and in his search for theories that explain patterns of variations in populations in terms of mechanisms that operate on individuals over history (Harman and Troch, 2014). A Darwinian approach to catchment hydrology would echo this focus. The primary data for Darwinian hydrology would likewise combine detailed analysis of the signatures of holistic hydrologic function in individual catchments, and the functional patterns that emerge when many catchments are compared on the basis of functional similarity, giving rise to the notion of comparative hydrology (Falkenmark and Chapman, 1989; Jothityangkoon et al., 2001; McDonnell et al., 2007; Blöschl et al., 2013), see also Sect. 4.2.3 on catchment similarity. 
The objective is to find generalizable mechanisms of landscape change that apply to a range of places that share broad conditions (Ghiselin, 1969; Kleinhans et al., 2010; Gupta et al., 2013). For example, it appears that there is a consistent trajectory of hydrologic evolution in upland basaltic watersheds from groundwater dominated in relatively young landscapes to shallow subsurface lateral flow in older ones, as the works of Lohse and Dietrich (2005) and Jefferson et al. (2010) indicate. These findings suggest that one may be able to find predictive relationships between the degree of drainage incision (a topographic signature of the older watersheds) and hydrologic partitioning in landscapes with a similar history.

The kind of understanding the Darwinian approach yields could have direct practical utility in the parameterization of hydrologic models. At the moment, any understanding a hydrologic modeler has about the historical evolution of a watershed's hydrologic system provides very little constraint on model structure and parameters. The understanding might be brought in implicitly through the choices the modeler makes in choosing a particular model structure, setting the model (e.g. by transferring parameters from nearby catchments, which most often share the same historical evolution), but there is not much in the way of frameworks or theory to do this in a systematic or rigorous way. Understanding the way co-evolution generates interdependency between landscape properties may yield ways of constraining unobserved hydrologic behaviour using new types of observable information (such as novel geophysical observations), or existing types in new ways (such as the spatial distribution of vegetation).

The coupling between predictions based on co-evolution and particular mechanisms of watershed change suggests that a catchment classification system based on a shared developmental pathway ("genotypes") may be more fruitful than one based on similar current hydrologic behaviour alone ("phenotypes") (for the latter, see Sect. 4.2.3). Approaches for testing such explanatory theories have been widely discussed in the geology and ecology literature (Chamberlin, 1890; Rhoads and Thorn, 1996), Srinivasan et al. (2012) offers a nice recent example of how this type of thinking can be applied to socio-hydrologic questions (Sivapalan et al., 2012). The potential added value of a classification system based on developmental pathways is dependent on the degree to which signatures of structure-shaping processes are preserved in current structure. Or, in other words, it depends on the degree of determinism of its evolution which, in Fig. 1, can be associated with the number of points of instability a system crosses during its evolution. An example for strong determinism is structured soil created by repeated volcano eruptions during the last millennia; a turbulent flow structure marks the other extreme (weak determinism), as here knowledge of current structure will not allow exact reconstruction of its developmental pathway.
Note that it should be uncontroversial to suggest that catchments "evolve" since this simply implies change over time, and says nothing about the mechanism of that change. Similarly "co-evolution" in this context is simply the hypothesis that changes in hydrology, topography, soils, ecosystems and human activities are interdependent. Darwin's “theory of evolution" was not a proposal that evolution occurs (that idea had been around for centuries) but rather a mechanism for that change that unifies and explains observed patterns of variations in species (i.e. natural selection). Darwinian hydrology could similarly search for ways to unify the variability of catchments' hydrologic behaviour, but will have to search for its own mechanisms, since clearly "natural selection" applies only to the biotic components of a hydrological system.

Rather than a single "new theory", the Darwinian approach to hydrology aims to develop a body of knowledge and wisdom about landscapes that provides constraints on the current and future unknown parameters (or perhaps on the hydrologic fluxes themselves, bypassing the need for such parameters). This knowledge should be predicated on a set of theories that explain and predict the co-evolution of the hydrologic functioning of the landscapes as a whole, locally dependent on the smaller set of key historical and contemporary forces (climate and geology) that have conditioned and constrained that evolution. In this sense there is a clear need for a synthesis of the traditional "Newtonian" approaches that involve the study of individual catchments and "Darwinian" approaches that are based on the comparative study of populations of catchments, as called for in a series of papers culminating in the most recent outcome of the IAHS Decade on Predictions in Ungauged Basins initiative (Sivapalan, 2005; McDonnell et al., 2007; Sivapalan et al., 2011; Blöschl et al., 2013; Gupta et al., 2014). The question is open whether Darwinian theories and constraints can be found and used to constrain and test predictive reductionist models.

\subsubsection{Catchment similarity}

Catchment similarity, in a hydrologic sense, refers to the question why two catchments exhibit similar hydrologic response characteristics (Wagener et al., 2007). Catchment similarity is the basis for catchment classification, for transferability of information, for generalization of our hydrologic understanding and also for understanding the potential impacts of environmental change (McDonnell and Woods, 2004). The apparent similarity of many catchments around the world is likely rooted in their shared principles that guide catchment evolution over time and on their shared emergent effects (see Sect. 4.2.1). Comparing catchments of presumably common initial and boundary conditions with respect to their dissimilarities therefore gives insight into remaining degrees of freedom, while comparing them with respect to their similarities gives insight into universal constraints of catchment evolution. Typically, this similarity is assessed by 
estimating the distance between two catchments in a suitably chosen metric space, although careful exploration of the consequences of choices made regarding distance measures and potential clustering approaches is necessary to understand their impact on the similarity analysis results. An overview of techniques and measures to quantify similarity of catchment structure, function and response on various scales is given in Wagener et al. (2007). Blöschl et al. (2013) organize their comparative assessment of runoff predictions in ungauged basins around the notions of catchment, climate and hydrological similarity.

For example, catchments satisfying the Budyko curve (Budyko, 1974) manifest the similarity of long-term hydrologic functions (partitioning of precipitation into rainfall, runoff and evapotranspiration) under stationary climatic controls; while the deviation from the Budyko curve might manifest the remaining degrees of freedom such as vegetation and landscape variations (Troch et al., 2013). However, the current state of this issue should be treated with caution. There have been a range of studies showing that, in a modelled environment, differences between catchments in vegetation cover or soil types can reproduce the deviations from the Budyko curve that have been observed in many empirical studies using different assumptions (e.g. Troch et al., 2013). However, given that any empirical study is based on observations with unavoidable errors, it is not yet clear when deviations from the Budyko curve, which assumes climatic control only, are due to actual differences in landscape characteristics and where it might be the result of data error. More research is needed to separate the two.

The similarity of climate control on base flow and perennial stream density shows the common constraints on shallow groundwater discharge and basic stream network formation (Wang and Wu, 2013). Similarity in geology (e.g. karst versus non-karst) is reflected in the strength with which an incoming precipitation signal is filtered (damped) by a catchment, so that strongly different flow regimes can be observed even under similar rainfall regimes (e.g. Tague and Grant, 2004). Land use will also create hydrologic differences between otherwise similar catchments (similar in pedology, geology, and climate). For example, differences between mature forest and pasture landscapes in neighboring catchments in Mexico become clear under more intense storms (once every 2 yr) (Muñoz-Villers and McDonnell, 2013). Under those conditions, the infiltration capacity of the pasture is exceeded and event water contributions are much higher than for the forested landscapes even though both overlay rather permeable volcanic soils.

The difficulty in assessing the degree of similarity and dissimilarity is unfortunately most often complicated through the interaction of multiple physical characteristics (e.g. a mixture of geologies), which does not allow for a very clear separation in many cases. For example, Martin et al. (2012) concluded that the degree of urbanization in US catchments had to exceed about $15 \%$ before hydrological signatures could be differentiated between urbanized and non-urbanized catchments. Given this ambiguity and our limited ability to exactly estimate the physical characteristics of a catchment, it is often necessary to resort to the use of dynamic models in which the physical system is parameterized (Carrillo et al., 2011). As a consequence, we still have to face the widely discussed issues of equifinality and model structural uncertainty.

Searching for hydrologic similarities and their organizing principles can help to estimate the future behaviour of existing catchments under changed boundary conditions by trading space for time (Singh et al., 2011). The question of whether spatial and temporal variability can be traded in hydrology has so far been insufficiently addressed. There have been some initial studies that indeed suggest that the approach might be useful to derive priors on model parameters or catchment behaviour for catchments that underwent change. This idea is of course similar to the transfer of information from a sufficiently similar catchment before and after a distinct change has occurred (e.g. deforestation). Questions about what degree of similarity is needed in this context still remain open. The more recent trading-space-for-time papers are more concerned with the very long-term impacts of climate change (and how climate for example might impact parameter values).

The question can be more complex in cases where the changes are primarily anthropogenic and are not similar to changes that could naturally occur (e.g. urbanization vs. deforestation). Here it matters more what the type of change is that is investigated. Changes such as deforestation can use information from other catchments (under assumed similarity), while impacts such as urbanization might have too unique a signature for information to be transferrable. It is in many cases not even possible to understand in how far the signature of the changed catchment has been influenced unless the change is very large, for example, in the case of urbanization (e.g. Martin et al., 2012).

\subsection{Catchments as open dissipative systems far from equilibrium}

Since its beginnings with the work of Carnot and Clausius in the 19th century, thermodynamics has been recognized as a fundamental theory about nature (Klein, 1967) and has so far proven to be applicable to any natural system, be it physical, chemical or biological. While its first law essentially states the conservation and convertibility of energy, the second law states that in isolated systems, the entropy of the system can only increase. Entropy is a physical property of the system that describes the extent to which energy is dispersed (unavailable to perform work) within the system. In other words, spontaneous processes always deplete (and never establish) potential gradients, thereby increasing the system's entropy. The second law describes irreversibility caused by dissipative processes such as heat transfer, friction, chemical reactions 
and diffusion and hence introduces an arrow of time to natural processes (Eddington, 1928).

Viewing catchments as open, dissipative thermodynamic systems far from equilibrium in the framework of thermodynamics offers several advantages. We will discuss them by first addressing what these terms imply using the example of heat transport in a reservoir heated at the bottom and cooled at the top (the well-known Benard experiment, see Fig. 1): the state of any thermodynamic system can be characterized by a set of macroscopic state variables and a unique stable state termed thermodynamic equilibrium (TE) at which it will arrive in isolation. The reservoir in Fig. 1 is in TE if the temperature gradient between the top $\left(T_{o}\right)$ and the bottom $\left(T_{u}\right)$ is zero. If the system is open, (i.e. it exchanges mass, momentum, energy and entropy with the environment) but sufficiently close to TE, there exists a unique steady state it will attain. Along this continuous set of steady states termed "thermodynamic branch", linear relations between the system components dominate. In the reservoir (Fig. 1), this is associated with conductive heat transport, which is a linear function of the temperature gradient $\left(T_{u}-T_{o}\right)$.

Along the thermodynamic path (including TE), systems invariably settle to a state of minimum Entropy Production (minEP) (Kondepudi and Prigogine, 1998). If an open system in steady state is, however, kept sufficiently far from TE (openness being, in fact, a precondition for this), nonlinear relations and cooperative micro-processes among system components can start to predominate, the thermodynamic branch can become unstable and, triggered by random microperturbations, bifurcations can lead to several branches of possible stable steady states. Sufficient distance from TE is hence a precondition for self-organization to occur (see Sect. 4.2.1).

In the reservoir, self-organization occurs in the form of convective cells if a critical temperature gradient $\mathrm{d} T_{\text {crit, } 1}$ is exceeded. All stable steady states after the point of instability of the thermodynamic branch are called "dissipative branch", all systems along it "dissipative systems", as here energy fluxes and energy dissipation are increased compared to systems on the thermodynamic branch. Increasing distance from TE is often associated with higher system structure (in Fig. 1 the existence of macroscopic convective cells) and stable dissipative systems typically settle to steady states of maximum entropy production (maxEP) as the most probable states (e.g. Dewar, 2005; Virgo, 2010).

Moving still further from TE, systems may reach further points of instability, in the case of the reservoir this is marked by a transition from convective to turbulent flow at $\mathrm{d} T_{\text {crit, } 2}$. The relation between the distance from TE, self-organization associated with structure formation, accelerated dynamics and entropy production shown in Fig. 1 can also be applied to water flow through cohesive, erodible soils. Close to TE (here expressed by a small hydraulic gradient), diffusive water flow is linearly dependent on the hydraulic gradient. Beyond a critical hydraulic gradient, subsurface backward erosion can lead to the formation of (dissipative) preferential flow structures which accelerate the flow and add an entirely new quality to it. Most hydrological systems of interest can be viewed as dissipative structures, exchanging mass, energy and entropy with the environment, being kept far from TE by solar radiation or mantle convection (directly or indirectly), being composed of many sub-systems connected by highly nonlinear relations, exhibiting dissipative processes such as radiation, soil heat flow, frictional water flow, diffusion, or photosynthesis. Thermodynamics therefore lends itself as a framework to deal with catchments as complex dynamical systems (Sect. 4.1), catchment self-organization (Sect. 4.2.1) and co-evolution (Sect. 4.2.2).

So what does application of a thermodynamic perspective to hydrological systems actually imply? At a minimum, it comprises the definition of the system (i.e. its boundary and relevant sub-systems), keeping track of mass-, energy-, momentum- and entropy budgets while ensuring conservation of mass, energy and momentum and establishment of all relevant thermodynamic state variables. Further, all dynamics should be expressed on the basis of paired (conjugate) variables: the gradient of one of the two variables is depleted by the flux of the other; together they always describe a form of energy. For example, a gradient in geopotential fuels a mass flux, which eventually depletes the gradient. Together, mass $[\mathrm{kg}]$ and the gradient in geopotential $\left[\mathrm{m}^{2} \mathrm{~s}^{-2}\right]$ describe energy in the form of potential energy [J] (see also Kondepudi and Prigogine, 1998 or Kleidon, 2010). The direct benefit is that thus relating dynamics to the universal "currency" of energy provides a link between any kind of process, be it abiotic, biotic, or anthropogenic. Moreover, it puts emphasis on the role of feedbacks: based on the above general form, fluxes are equal to a driving gradient divided by a resistance term, which is essentially a linear process. Nonlinearity then enters dynamics in the form of feedbacks: any flux depleting its nourishing gradient is associated with a negative feedback, positive feedbacks can occur through local enhancement of the gradient (e.g. formation of locally steepened hill slopes which increase fluxes of water and sediment, Kleidon et al., 2013) or by local decrease of the resistance (e.g. by formation of low-friction drainage networks, Kleidon et al., 2013, or by the decreasing flow resistance of soil caused by wetting). It should be noted that by far not all processes create such positive feedbacks, but the point is that in principle they can (and some do). This is the only reason a system can by itself evolve locally farther from TE, yet still obeying the direction dictated by the second law at a broader scale.

For prediction of catchments under change, an explicit representation of such feedbacks is vital, as for systems far from TE, it is the balance of positive and negative feedbacks that keeps them in or pushes them out of stable quasisteady states. Further, expressing dynamics via a concept of cascading energy conversions along hierarchical thermodynamic gradients (see Fig. 2) leads to a natural hierarchy of 


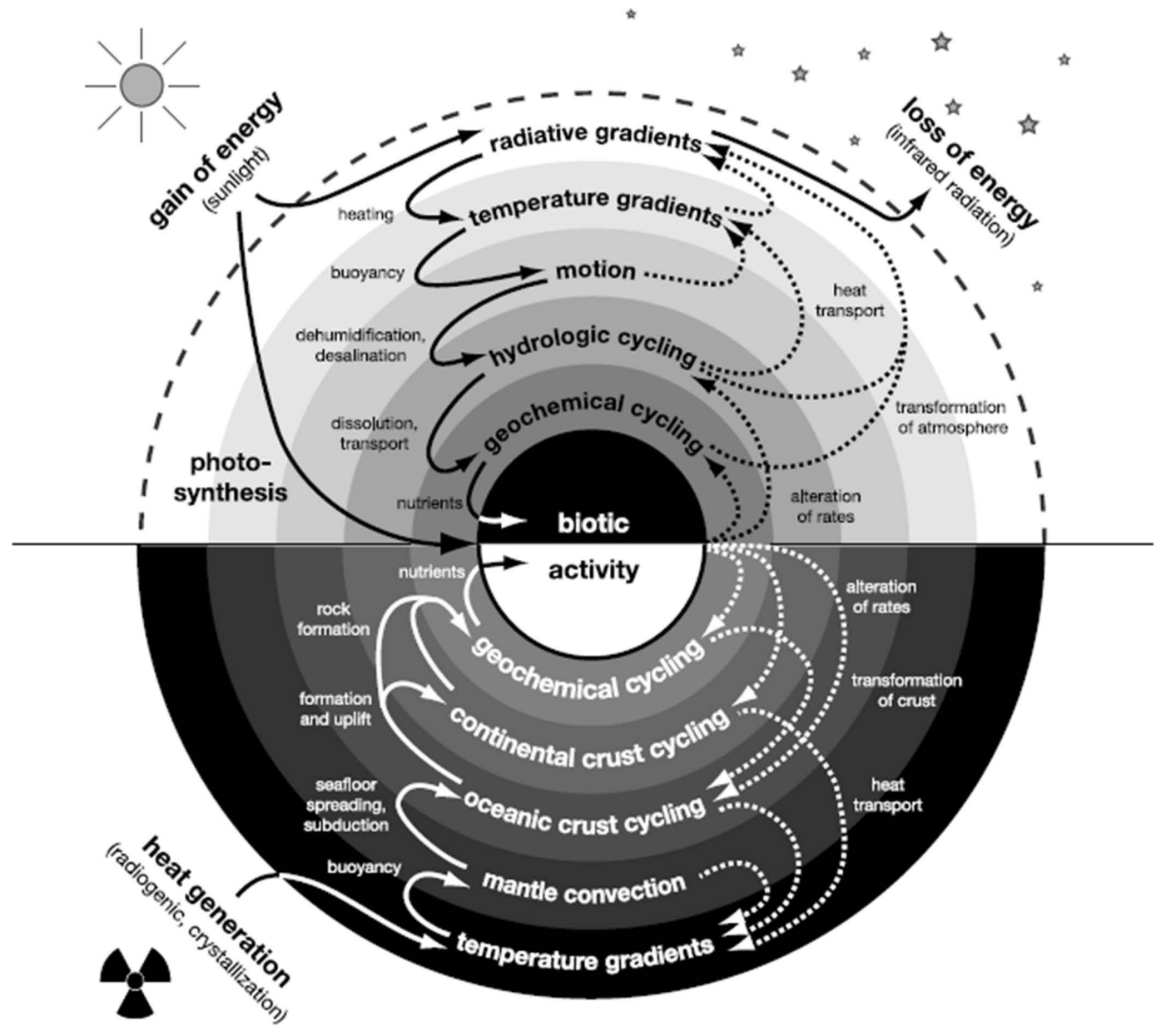

Fig. 2. Simplified summary of a hierarchy of power transfer among earth system processes. Solid arrows describe flows of energy, while dotted arrows describe effects. From Kleidon (2010).

processes which is useful, not only to establish hierarchical modelling concepts, but also to allow formulation of upper thermodynamic limits to the magnitude of each conversion process (see e.g. Kleidon and Renner, 2013a). Knowledge of such upper limits can be helpful to assess the effects of climate change to catchment dynamics. One example of such an application is given by Kleidon and Renner (2013b), who derived the sensitivity of the hydrologic cycle to surface warming that matches the results of vastly more complex climate models very well.

\subsubsection{Optimality principles}

Analysis of non-equilibrium systems has led to the proposition of extremum or optimality principles such as minEP (see above) and maxEP (Paltridge, 1978; Ozawa et al., 2003; Kleidon and Lorenz, 2005; Dewar, 2005), which direct their development towards final steady states. For transient dissipative systems with many degrees of freedom, they can therefore be used as "selection criteria" distinguishing more and less probable pathways of development. MaxEP, for example was proposed for prediction of the partitioning of water between evapotranspiration and runoff (Kleidon and Schymanski, 2008) and was used to predict effective global transfer coefficients for root water uptake and base flow (Porada et al., 2011), and for the effects of vegetation banding on aggregated biomass and water fluxes (Schymanski et al., 2010).

Closely related to maxEP, it has recently been suggested that dissipative systems develop such that the time to reach TE is minimized, or in other words that work done over time (power) by the system is maximized (maximum Power Principle maxP, Kleidon, 2010; Kleidon et al., 2013). Recently, Zehe et al. (2013) have shown that the choice of macroporosity as optimal with respect to maxP has allowed calibrationfree reproduction of observed hillslope hydrological dynamics. Optimality principles can thus reduce data demands and the need for calibration, which is especially useful for transient or ungauged catchments. Many other optimality principles have been proposed, such as maximization of gross or net primary productivity to predict biomass dynamics or 
maximum net carbon profit to predict vegetation water use (Schynamski et al., 2009). It has been suggested, however, that upon choosing system extent and scale of consideration appropriately, many can be translated to maxEP (Dewar, 2010).

Disturbance of steady-state dissipative systems can either leave them unaffected or cause build-up or decay of structure, depending on the system's position on the dissipative branch (proximity to points of instability, see Fig. 1) and the strength and nature of the disturbance. Viewing catchments under change as complex, dynamical (see Sect. 4.1) and dissipative systems can therefore provide a framework to evaluate their stability, resilience and predictability. Last but not least, adding energy considerations to the analysis and prediction of hydrological systems offers additional observables which can help to better determine system dimensionality and to represent and constrain system dynamics.

\subsection{Catchments as sources and flow paths of information}

The next perspective we take is that of information theory. It focuses on the way information is extracted from data, how it can be compressed, stored, communicated in the form of explanations, and its relation to uncertainty. Although important foundations were laid earlier, the birth of Information theory is mainly attributed to the seminal paper by Shannon (1948), who defined information and uncertainty as quantities that can be represented, for example, as bits (binary digits). Information theory is closely related to probability theory, but was developed relatively independently from statistics, where, for example, the different definition of Fisher information exists, instead evolving mainly from advances in the fields of cryptography, communication engineering and signal processing. The adoption of Shannon's information theory back into statistics is mainly due to the principle of maximum entropy (Jaynes, 1957). Also, information theory has been widely applied in the hydrological literature, see for example the review papers by Singh and Rajagopal (1987), Singh (1997) and recent papers by Brunsell (2010), Ruddell and Kumar (2009a, b) and many more. In this paper, we focus on the role information theory can play in analysing and optimizing the way information feeds into predictions.

As "information" is a universal quantity, information theory is a potentially useful framework in which the information content, for a given purpose, across data, scientific laws, model structures and model parameters can be evaluated. Its primary value with respect to addressing questions of change is therefore not so much in its direct application to such problems, but rather by providing a basis for the evaluation and improvement of predictive models by learning from data.

"Information" can be viewed as a quantity that connects processes and quantities in the real world with conceptual representations of those processes and quantities in our minds, or in computers. To understand this, note that "observation" consists of a process by which attention to a quantity under investigation brings about some kind of change of state - in a brain this can be a change in potential level of one or more neurons, and in a computer this can be the change in value of a bit within memory. Arguably, all of the knowledge accumulated about a catchment eventually stems from observations (including perceptions), and this then provides the information upon which our mental and computer models are based.

As mentioned earlier in Sect. 2, all observations about reality are converted into representations of knowledge by a process of "explanation", which can be viewed as a form of compression (Weijs et al., 2013a) in which a compact conceptual and/or mathematical description is used to describe/represent the structures that exist in the observations. If enough observations are present, if the noise in the observations is not too large, and if the structure is sufficiently strong and unchanging (i.e. consistent co-variation among the variables actually exists, and is not strongly dependent on non-observed variables, at the space-time scale of interest), then these compact descriptions will represent any relevant structure in the data and therefore most likely describe the general laws that can be deduced from the observations. These descriptions will then allow the transfer of relevant information contained within those observations, to other, sufficiently similar situations, thereby allowing the values of unobserved quantities to be predicted and decisions to be made regarding our interactions with the real system.

\subsubsection{Representing information and its role in the reduction of uncertainty}

According to Shannon (1948), uncertainty or missing information is viewed as being connected to the process of "choice" (decision making) and is represented in terms of the probabilities associated with different possible outcomes of an event. For events that can take on a discrete number " $n$ " of possible outcomes $(i=1, \ldots n)$, the measure for uncertainty, called information entropy $(H)$, is defined as the expected value of the negative $\log$-probability, $-\log _{b} P(i)$, of those outcomes, given as (there is also an analogous definition for continuous variables)

$H=E\left\{-\log _{b} P(i)\right\}=\sum_{i=1}^{n}-\log _{b} P(i) \cdot P(i)$.

Since anything that contributes to our knowledge/understanding about the value of an event can be thought of contributing to a change in our prior state of uncertainty (expressed in terms of a distribution of probabilities) about the value of that event, a gain in information can be defined as a change in uncertainty (Cover and Thomas, 2006). Alternatively, when observing an event, the gain in information can be equated to the "surprisal" caused (i.e. the extent to which the new observation is unexpected), which 
was defined by Shannon to be $-\log _{b} P(i)$, where $b$ can be chosen in some convenient fashion. Therefore, the entropy $(H)$ can be interpreted as the "expected surprise" about the true outcome.

In a more general sense, the probabilities referred to above can be thought of as reflecting states of knowledge (instead of just representing frequencies of occurrence), and we can adopt a more general (Bayesian) view in which probability distributions are used to represent (incomplete) information, and in which the axioms of probability function as the rules for logical reasoning (Jaynes, 2003). In general, it is important to recognize that misinformation can result in an incorrect inference about the true outcome, or the correct inference for the wrong reasons (Kirchner, 2006; Gupta et al., 2008; Nearing et al., 2013a, b) and that information can also be misapplied (e.g. through misapplications or imperfections in the applications of Bayes Law). Further, information content of a data set depends on the question being asked, and hence it is not just information we care about, but the usefulness and usage of the information.

\subsubsection{Applying concepts of information theory to catchment hydrology - potential and limitations}

Information theory provides a formal framework for linking observations, laws, models, and computerized algorithms. It therefore has the potential to play an important part in a theory of evaluation (Gupta et al., 1998, 2008, 2012) that facilitates a robust investigation and improvement of model performance (Gong et al., 2013), and in the evaluation of models of different degrees of complexity as in the case of multiple working hypotheses (Solomonoff, 1964; Clark et al., 2011). Information theory also can provide a framework to optimize strategies of data collection (Alfonso et al., 2010; Mishra and Coulibaly, 2010; Li et al., 2012, Gupta et al., 2013) and data assimilation (Nearing, 2013; Nearing et al., 2013a, b) in catchment hydrology. As information and uncertainty are closely linked (see Sect. 4.4.1), this framework is also potentially suited for quantification and minimization of uncertainty associated with decisions, e.g. in water resources management (Weijs et al., 2010) or choices of model structure (Nearing, 2013; Gong et al., 2013).

When applying information theory in practice, however, we should keep in mind that information theoretical quantities depend on probabilities, which in turn depend on states of (prior) knowledge. So results will depend importantly on our prior knowledge and how we choose to formalize it, which adds subjectivity and non-uniqueness to the processes of evaluation and prediction. For example, a time series of perfectly measured discharge contains, $N \cdot H(Q)$ bits of information for specifying what the discharge is at every time step, where $N$ is the length of the time series and $H(Q)$ is the entropy of the suitably (subjectively depending on the question asked) binned discrete distribution (histogram) of $Q$, but this assumes knowledge of the frequency distribution and no knowledge of or learning from temporal dependencies. When taking these dependencies into account, the information content is equal to the joint entropy of the entire series, and the frequency-based approach breaks down, since the joint entropy depends on an N-dimensional histogram with one observation. Alternatively, the joint entropy can be approximated by the conditional entropy of $Q_{t}$, given $Q_{t-L} \ldots Q_{t-1}$. This last quantity involves a model for predicting $Q$ from its previous $L$ time steps, with the model structure assumed to be known (e.g. Gong et al., 2013). Models of different complexity will give different answers. If the models are not known a priori, but inferred from the data, the model description length in bits should be added to the information content (Weijs et al., 2013a). Finally, in the hypothetical case that meteorological conditions and all hydrological processes are already perfectly known, the information content of the discharge series becomes zero, because the perfectly predictable values no longer contain any surprise. In other words, the goal of prediction is to make information from ex-post observations of the predicted variable as redundant as possible.

To summarize, applying concepts of information theory to catchment hydrology does not eliminate subjectivity associated with the way we treat prior knowledge, but it forces us to be more explicit about it and about the way it affects our predictions and decisions.

\section{Summary and conclusions}

We started from two observations: the first was that the hydrological cycle is increasingly affected by changes, which extend from local to global scale, act on short to decadal timescales and affect all characteristics of water-related dynamics. Humans play a double role in this, as they cause many of these changes and are at the same time concerned by them, thus demanding answers regarding the hydrological effects of global change. These changes potentially push hydrological systems out of the quasi-steady states they have reached through long-term co-evolution of their constituents, giving rise to the interplay of feedback effects which determine the systems path towards new stable states. The second observation was that the questions posed to hydrology have become increasingly complex, requiring the joint consideration of increasingly larger numbers of (sub-) systems and their interactions across more and longer timescales. Taken together, the two phenomena reduce the applicability of established hydrological concepts developed under in many aspects stationary conditions and for less complex systems.

Therefore, the main focus we have pursued in this article is to present and discuss paradigms and theories which we consider helpful to advance hydrology towards understanding and predicting the nature and behaviour of complex hydrological systems under change. To this end, we began with a discussion of the general nature of explanation in hydrology, 


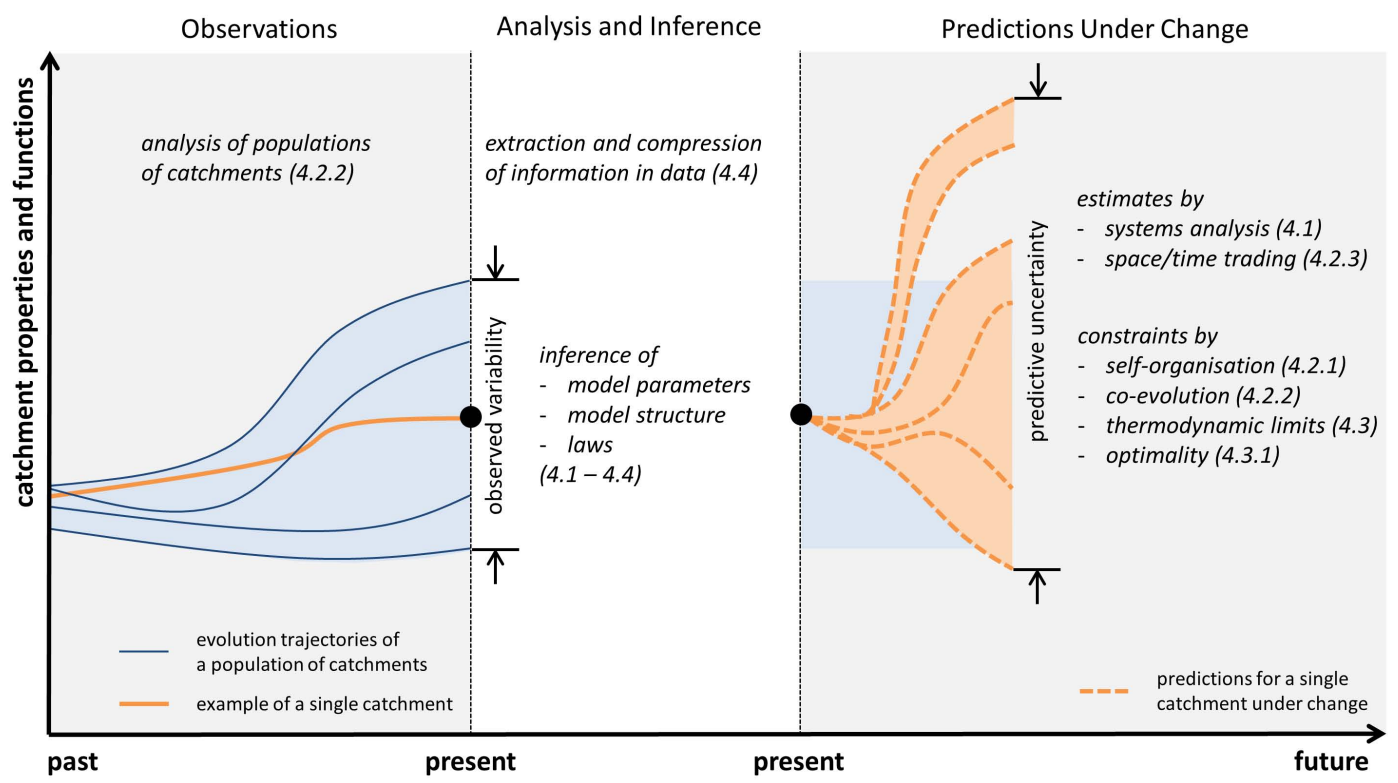

Fig. 3. Overview and connection of the paradigms discussed in the paper to improve hydrological predictions under change.

which is characterized by considerable pluralism stemming from different explanation types, the interdisciplinary nature of hydrology and underdetermination.

We continued by discussing the special characteristics of catchments, namely straightforward closure of the water balance due to convergence and existence of distinctly separate process scales for water flow and structure formation. Both have favoured development of simple, but successful sectoral hydrological models based on the assumption of stationarity, linear concepts and limited availability of observations. From this, we proposed several perspectives on catchments to deal with transient conditions (an overview is shown in Fig. 3): treating catchments as complex dynamical systems offers ways to classify them (Table 1) and to assess their stability, resilience and predictability. Looking at catchments from the point of view of the related field of synergetics highlights the occurrence of self-organization and emergence of macro-scale structures (spatial, temporal or functional). The advantage of exploiting such phenomena is that it greatly reduces the systems' degrees of freedom to the number of order parameters, making predictions a more straightforward task. It can also help to explain the apparent similarity of many catchments.

The next viewpoint we adopted is that of catchments as co-evolving systems, focusing on the mutual historical evolution of catchment constituents, and learning from analysis of the similarities and dissimilarities of catchments that started from presumably similar conditions in the past (Fig. 3). This is closely related to the analysis of catchment similarities, and both can help to provide constraints on parameters of predictive models and to transfer information among catchments in "space-for-time" trading approaches.
The thermodynamic view of catchments focuses on stocks, fluxes, conversions and dissipation of energy. Treating catchments as open dissipative thermodynamic systems far from equilibrium offers a framework which explains both the fundamental tendency towards degradation of structure, but also the preconditions for its build-up, whose interplay plays an important role in the evolution of hydrological systems over time. The benefit of expressing dynamics in the universal "currency" of energy is that it provides a link between any kind of process, be it abiotic, biotic, or anthropogenic. Also, optimality principles formulated in the fundamental terms of energy and entropy can potentially be applied to direct the development and prediction of new stable states of systems under change.

Then we took the perspective of information theory, which offers an alternative view on the nature of explanation (as data compression) and a general framework for the evaluation of information content (expressed in terms of the change in uncertainty about a target quantity of interest), across data, laws, and models. This makes it potentially a useful part in a theory of evaluation that facilitates critical assessment and improvement of predictive models.

In their article on the nature of explanation in the earth sciences, Kleinhans et al. (2005) conclude that the best way to overcome underdetermination is a combination of historical actual-sequence explanations, robust process explanations and causal explanations in the form of laws. We adopt this view for hydrological systems, and especially hydrological systems under change, which is reflected in the previously proposed perspectives on catchments (see Fig. 3): analysing catchment co-evolution provides insight into the historical development of actual catchments and potentially 
robust process explanations of the underlying mechanisms. Applying the methods of complex system analysis to catchments under change can provide general statements on predictability, and allows linkage of existing scale-specific hydrological laws, when seen as manifestations of emergent phenomena on different macroscopic scales. Expressing dynamics on the basis of the universal laws of thermodynamics facilitates linking all the processes involved in the hydrological cycle and allows formulation of constraints to its dynamics. Finally, the information-theoretic view is both helpful as a common framework for the many modelling approaches in hydrology, and has links to the self-organization of systems (Kumar and Ruddell, 2010).

The approaches we have proposed as being useful for dealing with catchments under change are based on established theories. Nevertheless we suggest that they deserve closer attention and that their synergistic combination can, together with recent advances in observation technologies and in storing and sharing data (e.g. Hrachowitz et al., 2013 and references therein; OGC, 2012; Overeem et al., 2013; Selker et al., 2006; Schmelzbach et al., 2012), advance catchment hydrology to address questions of change.

Table A1. List of definitions (alphabetical order).

Co-evolution Joint evolution (see also "evolution") of several interacting components (abiotic and/or biotic) of a system. Biological co-evolution is the joint biological evolution of two species connected by conflicts or cooperation.

Evolution In this article we adopt the general meaning of evolution as gradual development of something. This can include the special case of biological evolution, which is characterized by natural selection leading to adaptation, speciation, divergence or extinction of species on the basis of inheritance, random mutation and recombination of genetic information.

Forecast Quantitative prediction for a given location at a specified future time.

Non-steady state No change of structure over time, but state variables and fluxes (within the system and across its borders) do change.

Paradigm World view or code of practice commonly accepted in a scientific field at a given time. It guides both the kind of questions (experiments, observations) that are being asked in a scientific field as well as the way the results are interpreted (e.g. Kuhn, 1970). It can include several scientific theories.
Prediction

Projection

Quasi-steady state

Scientific law:

Scientific theory

Stationary state

Steady state
Approximating an unknown state of a system with full, partial or no knowledge of initial and boundary conditions. In statistical terms it is the approximation of the actual but unknown realization of a stochastic variable.

Prediction of a possible future state of a system under certain assumptions (e.g. assumption of an emission scenario in climate projections). A projection hence cannot be associated with an occurrence probability.

Steady state for long (aggregation) timescales (steady state of long-term mean states and fluxes), but non-steady state for shorter timescales. See also "steady state".

Statements on causal relations among its constituents, exception free and irreducible within its scope (system, scale, boundary conditions). Laws are based on empirical evidence, can often be expressed by mathematical equations and hence be used in computer models.

Explanation of some aspect of the natural world, established by following the scientific method and confirmed by observation and experiment (empirical evidence). A theory has explanatory and predictive power; its strength is related to the parsimony of its principles, the diversity of phenomena it can explain and the quality of its falsifiable predictions (e.g. Popper, 2002). It can contain several scientific laws.

In this text used interchangeably with "steady state". In statistical terms: the underlying distribution of a random variable does not change with time.

No change of structure, states and net fluxes (within the system and across its borders) over time, at least one flux is non-zero. See also "quasi-steady state" and "stationary state". 
Structure

Thermodynamic

equilibrium (TE)

Transient state
General: any non-random deviation from a mean (spatial and/or temporal).

Hydrological modelling: any time-invariant system characteristic.

Algorithmic information theory: structure in data allows compression without loss of information.

Thermodynamics: a thermodynamic potential gradient.

No change of structure, states and fluxes (within the system and across its borders) over time, all fluxes are zero.

State of a system that undergoes structural changes over time.

Acknowledgements. The first author acknowledges support by Deutsche Forschungsgemeinschaft DFG and Open Access Publishing Fund of Karlsruhe Institute of Technology (KIT).

The second author was partially supported by a grant from the Co-operative Research Programme (Trade and Agriculture) of the Organization for European Co-Operation and Development (OECD).

This research contributes to the "Catchments As Organized Systems" (CAOS) research group funded by the Deutsche Forschungsgemeinschaft DFG.

We want to thank Keith Beven and an anonymous referee for their useful and constructive comments, which helped to improve the clarity of arguments presented in this manuscript.

The service charges for this open access publication have been covered by a Research Centre of the Helmholtz Association.

Edited by: D. Gerten

\section{References}

Abbott, M. B., Bathurst, J. C., Cunge, J. A., O’Connell, P. E., and Rasmussen, J.: An introduction to the European Hydrologic System - Système Hydrologique Européen, "SHE”, 1, History and philosophy of a physically-based, distributed modelling system, J. Hydrol., 87, 45-49, 1986.

Abramowitz, G., Gupta, H. V., Pitman, A., Wang, Y., and Leuning, R.: Neural Error Regression Diagnosis (NERD), A Tool for Model Bias Identification and Prognostic Data Assimilation, J. Hydrometeorol., 7, 160-177, 2006.

Abramowitz, G., Pitman, A., Gupta, H. V., Kowalczyk, E., and Wang, Y.: Systematic Bias in Land Surface Models, J. Hydrometeorol., 8, 989-1001, 2007.
Alfonso, L., Lobbrecht, A., and Price, R.: Information theory-based approach for location of monitoring water level gauges in polders, Water Resour. Res., 46, W03528, doi:10.1029/2009WR008101, 2010.

Ali, G., Oswald, C. J., Spence, C., Cammeraat, E. L. H., McGuire, K. J., Meixner, T., and Reaney, S. M.: Towards a unified threshold-based hydrological theory: necessary components and recurring challenges, Hydrol. Process., 27, 313-318, doi:10.1002/hyp.9560, 2013.

Ashby, W. R.: Principles of the self-organizing system, in: Principles of Self-Organization: Transactions of the University of Illinois Symposium, edited by: Von Foerster, H. and Zopf Jr., G. W., Pergamon Press, London, UK, 255-275, 1962.

Baker, V. R.: Paleoflood hydrology and Extraordinary Flood Events, J. Hydrol., 96, 79-99, doi:10.1016/0022-1694(87)90145-4, 1987.

Bardossy, A. and Caspary, H. J.: Detection of climate change in Europe by analyzing european atmospheric circulation patterns from 1881 to 1989, Theor. Appl. Climatol., 42, 155-167, doi:10.1007/bf00866871, 1990.

Bergström, S.: Development and Application of a Conceptual Runoff Model for Scandinavian Catchments, Dept. of Water Resour. Engineering, Bull. Ser. A, No. 52. Lund Inst. of Technol./Univ. of Lund, Lund, 134 pp., 1976.

Beven, K.: Changing ideas in hydrology - the case of physically based models, J. Hydrol., 105, 157-172, 1989.

Blöschl, G.: Hydrologic synthesis: across processes, places, and scales, Water Resour. Res. 42, W03S02, doi:10.1029/2005WR004319, 2006.

Blöschl, G. and Montanari, A.: Climate change impacts-throwing the dice?, Hydrol. Process., 24, 374-381, 2010.

Blöschl, G. and Sivapalan, M.: Scale issues in hydrological modelling - a review, Hydrol. Process., 9, 251-290, 1995.

Blöschl, G., Gutknecht, D., and Kirnbauer, R.: Distributed Snowmelt Simulations in an Alpine Catchment: 2. Parameter Study and Model Predictions, Water Resour. Res., 27, 31813188, doi:10.1029/91wr02251, 1991.

Blöschl, G., Sivapalan, M., Wagener, T., Viglione, A., and Savenije, H. H. G.: Runoff Prediction in Ungauged Basins - Synthesis Across Processes, Places and Scales, Cambridge University Press, Cambridge, UK, 2013.

Bossel, H.: Indicators for Sustainable Development: Theory, Method, Applications, International Institute for Sustainable Development, Winnipeg, Canada, 1999.

Bossel, H.: Dynamics of forest dieback: Systems analysis and simulation, Ecol. Model., 34, 259-288, doi:10.1016/0304 3800(86)90008-6, 1986.

Bossel, H.: Systems and Models, Complexity, Dynamics, Evolution, Sustainability, Books on Demand GmbH, Norderstedt, Germany, 372 pp., 2007.

Brandes, D., Duffy, C. J., and Cusumano, J. P.: Stability and damping in a dynamical model of hillslope hydrology, Water Resour Res., 34, 3303-3313, 1998.

Brunsell, N.: A multiscale information theory approach to assess spatial-temporal variability of daily precipitation, J. Hydrol., 385, 165-172, 2010.

Budyko, M. I.: Climate and Life, Academic, New York, 1974. 
Buol, S. W., Southard, R. J., Graham, R. C., and McDaniel, P. A.: Soil Genesis and Classification, 6th Edn., Wiley-Blackwell, Chichester, UK, 560 pp., 2011.

Burnash, R. J. C., Ferral, R. L., and McGuire, R. A.: A Generalized Streamflow Simulation System: Conceptual Models for Digital Computers, Joint Federal-State River Forecast Center, Sacramento, CA, 1973.

Carrillo, G., Troch, P. A., Sivapalan, M., Wagener, T., Harman, C., and Sawicz, K.: Catchment classification: hydrological analysis of catchment behavior through process-based modeling along a climate gradient, Hydrol. Earth Syst. Sci., 15, 3411-3430, doi:10.5194/hess-15-3411-2011, 2011.

Chaitin, G. J.: On the length of programs for computing finite binary sequences, J. ACM, 13, 547-569, 1966.

Chamberlin, T. C.: The method of multiple working hypotheses, Science, 15, 92-96, reprinted: 1965, 148, 754-759, 1890.

Clark, M. P., Kavetski, D., and Fenicia, F.: Pursuing the method of multiple working hypotheses for hydrological modeling, Water Resour. Res., 47, W09301, doi:10.1029/2010WR009827, 2011.

Corenblit, D., Baas, A. C. W., Bornette, G., Darrozes, J., Delmotte, S., Francis, R. A., Gurnell, A. M., Julien, F., Naiman, R. J., and Steiger, J.: Feedbacks between geomorphology and biota controlling Earth surface processes and landforms: a review of foundation concepts and current understandings, Earth-Sci. Rev., 106, 307-331, doi:10.1016/j.earscirev.2011.03.002, 2011.

Corrigendum to IPCC: http://www.pbl.nl/en/dossiers/ Climatechange/content/correction-wording-flood-risks, last access: 17 April 2013.

Cover, T. M. and Thomas, J. A.: Elements of Information Theory, John Wiley, Hoboken, N.J., 2006.

Crawford, N. H. and Linsley, R. K.: Digital Simulation in Hydrology: Stanford Watershed Model IV, Technical Report No. 39, Department of Civil Engineering, Stanford University, Stanford, California, USA, 210 pp., 1966.

Dai, Y., Zeng, X., Dickinson, R. E., Baker, I., Bonan, G. B., Bosilovich, M. G., Denning, A. S., Dirmeyer, P. A., Houser, P. R., Niu, G., Oleson, K. W., Schlosser, C. A., and Yang, Z.-L.: The Common Land Model, B. Am. Meteorol. Soc., 84, 10131023, 2003.

Demchenko, P. F. and Kislov, A. V.: Stochastic dynamics of natural objects, GEOS, Moscow, Russia, 189 pp., 2010.

Dewar, R. C.: Maximum entropy production and non-equilibrium statistical mechanics, in: Non-equilibrium Thermodynamics and the Production of Entropy, edited by: Kleidon, A. and Lorenz, R. D., Springer, Heidelberg, 41-55, 2005.

Dewar, R. C.: Maximum entropy production and plant optimization theories, Philos. T. Roy. Soc. B, 365, 1429-1435, doi:10.1098/rstb.2009.0293, 2010.

Dooge, J. C. I.: Linear Theory of Hydrologic Systems, Technical Bulletin No. 1468, Agricultural Research Service, United States Department of Agriculture, Washington, D.C., USA, 1327, 1973.

Dooge, J. C. I.: Looking for hydrologic laws, Water Resour. Res., 22, 46S-58S, 1986.

Eagleson, P. S.: Opportunities in the Hydrologic Sciences, National Academy Press, Washington, D.C., 1991.

Eddington, A. S.: The Nature of the Physical World, The Macmillan Company, New York, 1928
Falkenmark, M. and Chapman, T. G.: Comparative Hydrology: an Ecological Approach to Land and Water Resources, UNESCO, Paris, 1989.

Feynman, R.: The character of physical law, MIT Press, Cambridge, Massachusetts, 37-39, 1965.

Foley, J. A., DeFries, R., Asner, G. P., Barford, C., Bonan, G., Carpenter, S. R., Chapin, F. S., Coe, M. T., Daily, G. C., Gibbs, H. K., Helkowski, J. H., Holloway, T., Howard, E. A., Kucharik, C. J., Monfreda, C., Patz, J. A., Prentice, I. C., Ramankutty, N., and Snyder, P. K.: Global consequences of land use, Science, 309, 570-574, doi:10.1126/science.1111772, 2005.

Forrester, Jay W.: Principles of Systems, 2nd Edn., Productivity Press, Portland, OR, 391 pp., 1968.

Freeze, R. A. and Harlan, R. L.: Blueprint for a physically-based, digitally simulated hydrologic response model, J. Hydrol., 9, 237-258, 1969.

Gaál, L., Szolgay, J., Kohnová, S., Parajka, J., Merz, R., Viglione, A., and Blöschl, G.: Flood timescales: understanding the interplay of climate and catchment processes through comparative hydrology, Water Resour. Res., 48, W04511, doi:10.1029/2011WR011509, 2012.

Garcia-Garcia, F., Bohorquez, P., Martinez-Sanchez, C., PerezValera, F., Perez-Valera, L. A., Calero, J. A., and SanchezGomez, M.: Stratigraphic architecture and alluvial geoarchaeology of an ephemeral fluvial infilling: climatic versus anthropogenic factors controlling the Holocene fluvial evolution in southeastern Spain drylands, Catena, 104, 272-279, doi:10.1016/j.catena.2012.12.006, 2013.

Gaybullaev, B., Chen, S. C., and Kuo, Y. M.: Large-scale desiccation of the Aral Sea due to over-exploitation after 1960, J. Mt. Sci., 9, 538-546, doi:10.1007/s11629-012-2273-1, 2012.

Ghiselin, M. T.: The Triumph of the Darwinian Method, Dover Publications, New York, USA, 1969.

Gong, W., Gupta, H. V., Yang, D., Sricharan, K., and Hero, A. O.: Estimating epistemic and aleatory uncertainty during hydrologic modeling: an information theory approach, Water Resour. Res., 49, 1-21, doi:10.1002/wrcr.20161, 2013.

Grayson, R. B., Moore, I. D., and McMahon, T. A.: Physicallybased hydrologic modelling, 2. Is the concept realistic?, Water Resour. Res., 26, 2659-2666, 1992.

Grayson, R. B., Blöschl, G., Western, A. W., and McMahon, T. A.: Advances in the use of observed spatial patterns of catchment hydrological response, Adv. Water Resour., 25, 1313-1334, doi:10.1016/S0309-1708(02)00060-X, 2002.

Griffith, D., Solak, M., and Yorty, D.: 30+ winter seasons of operational cloud seeding in Utah, J. Weather Modificat., 41, 23-35, 2009.

Gumbel, E. J.: The return period of flood flows, Ann. Math. Stat., 12, 163-190, 1941

Gunnell, Y. and Krishnamurthy, A.: Past and present status of runoff harvesting systems in dryland peninsular India: a critical review, Ambio, 32, 320-324, doi:10.1579/0044-7447-32.4.320, 2003.

Gupta, H. V., Sorooshian, S., and Yapo, P. O.: Towards improved calibration of hydrologic models: multiple and noncommensurable measures of information, Water Resour. Res., 34, 751-763, 1998. 
Gupta, H. V., Bastidas, L., Sorooshian, S., Shuttleworth, W. J., and Yang, Z. L.: Parameter estimation of a land surface scheme using multi-criteria methods, J. Geophys. Res.-Atmos., 104, 1949119503, 1999.

Gupta, H. V., Wagener, T., and Liu, Y. Q.: Reconciling theory with observations: towards a diagnostic approach to model evaluation, Hydrol. Process., 22, 3802-3813, doi:10.1002/hyp.6989, 2008.

Gupta, H. V., Clark, M. P., Vrugt, J. A., Abramowitz, G., and Ye, M.: Towards a comprehensive assessment of model structural adequacy, Opinion paper, Water Resour. Res., 48, W08301, doi:10.1029/2011WR011044, 2012.

Gupta, H. V., Blöschl, G., McDonnell, J. J., Savenije, H. H. G., Sivapalan, M., Viglione, A., and Wagener, T.: Synthesis, chapt. 12, in: Runoff Predictions in Ungauged Basins: a Synthesis Across Processes, Places and Scales, edited by: Blöschl, G., Sivapalan, M., Wagener, T., Viglione, A., and Savenije, H., Cambridge University Press, Cambridge, UK, 361-383, 2013.

Gupta, H. V., Perrin, C., Blöschl, G., Montanari, A., Kumar, R., Clark, M., and Andréassian, V.: Large-sample hydrology: a need to balance depth with breadth, Hydrol. Earth Syst. Sci., 18, $463-$ 477, doi:10.5194/hess-18-463-2014, 2014.

Haken, H.: Synergetics, Naturwissenschaften, 67, 121-128, doi:10.1007/bf01073611, 1980.

Harman, C., and Troch, P. A.: What makes Darwinian hydrology "Darwinian"? Asking a different kind of question about landscapes, Hydrol. Earth Syst. Sci., 18, 417-433, doi:10.5194/hess18-417-2014, 2014.

Hasselmann, K.: Stochastic theory of climate, Part 1. Theory, Tellus, 28, 473-485, 1976.

Hastings, A., Hom, C. L., Ellner, S., Turchin, P., and Godfray, H. C. J.: Chaos in ecology - is mother nature a strange attractor?, Annu. Rev. Ecol. Syst., 24, 1-33, 1993.

Hawley, R. J. and Bledsoe, B. P.: How do flow peaks and durations change in suburbanizing semi-arid watersheds? A southern California case study, J. Hydrol., 405, 69-82, doi:10.1016/j.jhydrol.2011.05.011, 2011.

Heylighen, F.: Complexity and self-organization, in: Encyclopedia of Library and Information Sciences, edited by: Bates, M. J. and Maack, M. N., Taylor \& Francis, London, UK, 2008.

Hill, D. E. and Parlange, J. Y.: Wetting front instability in layered soils, Soil Sci. Soc. Am. Pro., 36, 697-702, 1972.

Hogue, T. S., Bastidas, L. A., Gupta, H. V., and Sorooshian, S.: Evaluating model performance and parameter behavior for varying levels of land surface model complexity, Water Resour. Res., 42, W08430, doi:10.1029/2005WR004440, 2006.

Hrachowitz, M., Savenije, H. H. G., Blöschl, G., McDonnell, J. J., Sivapalan, M., Pomeroy, J. W., Arheimer, B., Blume, T., Clark, M. P., Ehret, U., Fenicia, F., Freer, J. E., Gelfan, A., Gupta, H. V., Hughes, D. A., Hut, R. W., Montanari, A., Pande, S., Tetzlaff, D., Troch, P. A., Uhlenbrook, S., Wagener, T., Winsemius, H. C., Woods, R. A., Zehe, E., and Cudennec, C.: A decade of Predictions in Ungauged Basins (PUB) - a review, Hydrolog. Sci. J., 58, 1198-1255, doi:10.1080/02626667.2013.803183, 2013.

Huss, M.: Present and future contribution of glacier storage change to runoff from macroscale drainage basins in Europe, Water Resour. Res., 47, W07511, doi:10.1029/2010wr010299, 2011.
IPCC: Climate Change 2007: Synthesis Report. Contribution of Working Groups I, II and III to the Fourth Assessment Report of the Intergovernmental Panel on Climate Change, IPCC, Geneva, Switzerland, 104 pp., 2007.

Jaynes, E. T.: Information Theory and Statistical Mechanics, Phys. Rev., 106, 620-630, 1957.

Jaynes, E. T.: Probability Theory: the Logic of Science, Cambridge University Press, Cambridge, UK, 2003.

Jefferson, A., Grant, G. E., Lewis, S. L., and Lancaster, S. T.: Coevolution of hydrology and topography on a basalt landscape in the Oregon Cascade Range, USA, Earth Surf. Process., 35, 803816, doi:10.1002/esp.1976, 2010.

Jetschke, G.: Mathematik der Selbstorganisation, Verlag Harry Deutsch, Frankfurt a. M., Germany, 2009.

Jothityangkoon, C., Sivapalan, M., and Farmer, D. L.: Process controls of water balance variability in a large semi-arid catchment: downward approach to hydrological model development, J. Hydrol., 254, 174-198, doi:10.1016/S0022-1694(01)00496-6, 2001.

Kirchner, J. W.: Getting the right answers for the right reasons: Linking measurements, analyses, and models to advance the science of hydrology, Water Resour. Res., 42, W03S04, 10.1029/2005wr004362, 2006.

Kleidon, A.: Life, hierarchy, and the thermodynamic machinery of planet Earth, Phys. Life Rev., 7, 424-460, 2010.

Kleidon, A. and Lorenz, R. D.: Entropy production by earth system processes, in: Non-Equilibrium Thermodynamics and the Production of Entropy, edited by: Kleidon, A. and Lorenz, R. D., Springer, Heidelberg, 1-20, 2005.

Kleidon, A. and Renner, M.: Thermodynamic limits of hydrologic cycling within the Earth system: concepts, estimates and implications, Hydrol. Earth Syst. Sci., 17, 2873-2892, doi:10.5194/hess17-2873-2013, 2013a.

Kleidon, A. and Renner, M.: A simple explanation for the sensitivity of the hydrologic cycle to surface temperature and solar radiation and its implications for global climate change, Earth Syst. Dynam., 4, 455-465, doi:10.5194/esd-4-455-2013, 2013b.

Kleidon, A. and Schymanski, S.: Thermodynamics and optimality of the water budget on land: a review, Geophys. Res. Lett., 35, L20404, doi:10.1029/2008g1035393, 2008.

Kleidon, A., Zehe, E., Ehret, U., and Scherer, U.: Thermodynamics, maximum power, and the dynamics of preferential river flow structures at the continental scale, Hydrol. Earth Syst. Sci., 17, 225-251, doi:10.5194/hess-17-225-2013, 2013.

Klein, M. J.: Thermodynamics in Einstein's thought: thermodynamics played a special role in Einstein's early search for a unified foundation of physics, Science, 157, 509-516, doi:10.1126/science.157.3788.509, 1967.

Kleinhans, M. G., Buskes, C. J. J., and de Regt, H. W.: Terra Incognita: explanation and reduction in earth science, Int. Stud. Philos. Sci., 19, 289-317, doi:10.1080/02698590500462356, 2005.

Kleinhans, M. G., Bierkens, M. F. P., and van der Perk, M.: HESS Opinions On the use of laboratory experimentation: "Hydrologists, bring out shovels and garden hoses and hit the dirt", Hydrol. Earth Syst. Sci., 14, 369-382, doi:10.5194/hess-14-3692010, 2010.

Kolmogorov, A. N.: Three approaches to the quantitative definition of information, Int. J. Comput. Math., 2, 157-168, 1968. 
Kondepudi, D. and Prigogine, I.: Modern Thermodynamics: From Heat Engines to Dissipative Structures, John Wiley \& Sons Ltd, Chichester, England, 486 pp., 1998.

Koutsoyiannis, D.: On the quest for chaotic attractors in hydrological processes, Hydrolog. Sci. J., 51, 1065-1091, 2006.

Koutsoyiannis, D.: HESS Opinions "A random walk on water", Hydrol. Earth Syst. Sci., 14, 585-601, doi:10.5194/hess-14-5852010, 2010.

Koutsoyiannis, D., Montanari, A., Lins, H. F., and Cohn, T. A.: Climate, hydrology and freshwater: towards an interactive incorporation of hydrological experience into climate research, Hydrolog. Sci. J., 54, 394-405, 2009.

Kritsky, S. N. and Menkel, M. F.: On the methods of studying the random variations of river flows, Gidrometeoizdat, 1946.

Kuhn, T. S.: The structure of scientific revolutions, in: International Encyclopedia of Unified Science, 2nd Edn., edited by: Neurath, O., University of Chicago Press, Chicago, 1970.

Kumar, P.: Variability, feedback, and cooperative process dynamics: elements of a unifying hydrologic theory, Geogr. Compass, 1, 1338-1360, doi:10.1111/j.1749-8198.2007.00068.x, 2007.

Kumar, P.: Typology of hydrologic predictability, Water Resour. Res., 47, W00H05, doi:10.1029/2010WR009769, 2011.

Kumar, P. and Ruddell, B. L.: Information driven ecohydrologic self-organization, Entropy, 12, 2085-2096, doi:10.3390/e12102085, 2010.

Lehmann, P., Hinz, C., McGrath, G., Tromp-van Meerveld, H. J., and McDonnell, J. J.: Rainfall threshold for hillslope outflow: an emergent property of flow pathway connectivity, Hydrol. Earth Syst. Sci., 11, 1047-1063, doi:10.5194/hess-11-10472007, 2007.

Li, C., Singh, V., and Mishra, A.: Entropy theory-based criterion for hydrometric network evaluation and design: maximum information minimum redundancy, Water Resour. Res., 48, W05521, doi:10.1029/2011WR011251, 2012.

Lohse, K. A. and Dietrich, W. E.: Contrasting effects of soil development on hydrological properties and flow paths, Water Resour. Res., 41, W12419, doi:10.1029/2004WR003403, 2005.

Lorenz, E. N.: Predictability of a flow which possesses many scales of motion, Tellus, 21, 289-308, 1969.

Ludwig, K. and Bremicker, M.: The Water Balance Model LARSIM - Design, Content and Applications, Freiburger Schriften zur Hydrologie, Institut für Hydrologie, Uni Freiburg i. Br., Freiburg i. Br., 2006.

Martin, E. H., Kelleher, C., and Wagener, T.: Has urbanization changed ecological streamflow characteristics in Maine (USA)?, Hydrolog. Sci. J., 57, 1337-1354, doi:10.1080/02626667.2012.707318, 2012.

McDonnell, J. J. and Woods, R. A.: On the need for catchment classification, J. Hydrol., 299, 2-3, doi:10.1016/j.jhydrol.2004.09.003, 2004.

McDonnell, J. J., Sivapalan, M., Vache, K., Dunn, S., Grant, G., Haggerty, R., Hinz, C., Hooper, R., Kirchner, J., Roderick, M. L., Selker, J., and Weiler, M.: Moving beyond heterogeneity and process complexity: a new vision for watershed hydrology, Water Resour. Res., 43, W07301, doi:10.1029/2006wr005467, 2007.

Merz, R. and Blöschl, G.: Flood frequency hydrology: 1. Temporal, spatial, and causal expansion of information, Water Resour. Res., 44, W08432, doi:10.1029/2007wr006744, 2008.
Merz, R., Parajka, J., and Blöschl, G.: Time stability of catchment model parameters: implications for climate impact analyses, Water Resour. Res., 47, W02531, doi:10.1029/2010WR009505, 2011.

Mishra, A. and Coulibaly, P.: Hydrometric network evaluation for Canadian watersheds, J. Hydrol., 380, 420-437, 2010.

Montanari, A., Rosso, R., and Taqqu, M. S.: Fractionally differenced ARIMA models applied to hydrologic time series, Water Resour. Res., 33, 1035-1044, 1997.

Montanari, A., Young, G., Savenjie, H. H. G., Hughes, D., Wagener, T., Ren, L., Koutsoyiannis, D., Cudennec, C., Grimaldi, S., Blöschl, G., Sivapalan, M., Beven, K. J., Gupta, H. V., Arheimer, B., Huang, Y., Schumann, A., Post, D. A., Srinivasan, V., Boegh, E., Hubert, P., Harman, C. J., Thompson, S. E., Rogger, M., Hipsey, M., Toth, E., Viglione, A., Di Baldassarre, G., Schaefli, B., McMillan, H., Schymanski, S., Characklis, G., Yu, B., Pang, Z., and Belyaev, V.: "Panta Rhei - Everything Flows": Change in hydrology and society - The IAHS Scientific Decade 20132022, Hydrolog. Sci. J., 58, 1256-1275, 2013.

Mulvany, T. J.: On the use of self registering rain and flood gauges, Inst. Civ. Eng. Proc. (Dublin), 4, 1-8, 1850.

Muñoz-Villers, L. E. and McDonnell, J. J.: Land use change effects on runoff generation in a humid tropical montane cloud forest region, Hydrol. Earth Syst. Sci., 17, 3543-3560, doi:10.5194/hess17-3543-2013, 2013.

Nash, J. E., Eagleson, P. S., Philip, J. R., and van der Molen, W. H.: The education of hydrologists, Hydrolog. Sci. J., 35, 597-607, doi:10.1080/02626669009492466, 1990.

Nearing, G. S.: Diagnostics and Generalizations for Parametric State Estimation, Ph.D. Dissertation, Department of Hydrology and Water Resources, The University of Arizona, Tucson, AZ, USA, 2013.

Nearing, G. S., Gupta, H. V., Crow, W. T., and Wei, G.: An Approach to Quantifying the Efficiency of a Bayesian Filter, Water Resour. Res., 49, 1-10, doi:10.1002/wrcr.20177, 2013a.

Nearing, G. S., Gupta, H. V., and Crow, W. T.: Information loss in approximately Bayesian estimation techniques: A comparison of generative and discriminative approaches to estimating agricultural productivity, J. Hydrol., 507, 163-173, doi:10.1016/j.jhydrol.2013.10.029, 2013b.

OGC: The OGC adopts WaterML 2.0 Hydrologic Time Series Encoding Standard, OGC press releases, http://www. opengeospatial.org/node/1696 (last access: 8 November 2013), 2012.

Oreskes, N.: The role of quantitative models in science, in: Models in Ecosystem Science, edited by: Canham, C., Cole, J., and Lauenroth, W., Princeton University Press, Princeton, 2003.

Oreskes, N.: Beyond the ivory tower - the scientific consensus on climate change, Science, 306, 1686-1686, doi:10.1126/science.1103618, 2004.

Oreskes, N., Shraderfrechette, K., and Belitz, K.: Verification, validation, and confirmation of numerical models in the earth-sciences, Science, 263, 641-646, doi:10.1126/science.263.5147.641, 1994.

Overeem, A., Leijnse, H., and Uijlenhoet, R.: Country-wide rainfall maps from cellular communication networks, P. Natl. Acad. Sci., doi:10.1073/pnas.1217961110, in press, 2013. 
Ozawa, H., Ohmura, A., Lorenz, R. D., and Pujol, T.: The second law of thermodynamics and the global climate system: a review of the maximum entropy production principle, Rev. Geophys., 41, 1018, doi:10.1029/2002rg000113, 2003.

Paltridge, G. W.: The steady-state format of global climate, Q. J. Roy. Meteorol. Soc., 104, 927-945, doi:10.1002/qj.49710444206, 1978.

Phillips, J. D.: Instability and chaos in hillslope evolution, Am. J. Sci., 293, 25-48, 1993.

Phillips, J. D.: Deterministic chaos and historical geomorphology: a review and look forward, Geomorphology, 76, 109-121, doi:10.1016/j.geomorph.2005.10.004, 2006.

Poff, N. L., Bledsoe, B. P., and Cuhaciyan, C. O.: Hydrologic variation with land use across the contiguous United States: geomorphic and ecological consequences for stream ecosystems, Geomorphology, 79, 264-285, doi:10.1016/j.geomorph.2006.06.032, 2006.

Popper, K.: The Logic of Scientific Discovery, Routledge Classics, London, 2002.

Porada, P., Kleidon, A., and Schymanski, S. J.: Entropy production of soil hydrological processes and its maximisation, Earth Syst. Dynam., 2, 179-190, doi:10.5194/esd-2-179-2011, 2011.

Rhoads, B. L. and Thom, C. E.: The Scientific Nature of Geomorphology, in: Proceedings of the 27th Binghamton Symposium in Geomorphology held 27-29 September 1996, John Wiley \& Sons Limited, Canada, 115-143, 1996.

Ritsema, C. J., Dekker, L. W., Nieber, J. L., and Steenhuis, T. S.: Modeling and field evidence of finger formation and recurrence in a water repellent soil, Water Resour. Res., 34, 555-567, 1998.

Rodriguez-Iturbe, I., Entekhabi, D., and Bras, R. L.: Nonlinear dynamics of soil moisture at climate scales, 1. Stochastic analysis, Water Resour. Res., 27, 1899-1906, 1991.

Ropke, A., Stobbe, A., Oeggl, K., Kalis, A. J., and Tinner, W.: LateHolocene land-use history and environmental changes at the high altitudes of St Antonien (Switzerland, Northern Alps): combined evidence from pollen, soil and tree-ring analyses, Holocene, 21, 485-498, doi:10.1177/0959683610385727, 2011.

Rosolem, R., Gupta, H. V., Shuttleworth, W. J., de Goncalves, L. G. G., and Zeng, X.: Towards a comprehensive approach to parameter estimation in land surface parameterization schemes, Hydrol. Process., 27, 2075-2097, doi:10.1002/hyp.9362, 2013.

Ruddell, B. L. and Kumar, P.: Ecohydrologic process networks: 1. Identification, Water Resour. Res., 45, W03419, doi:10.1029/2008WR007279 2009a.

Ruddell, B. L. and Kumar, P.: Ecohydrologic process networks: 2. Analysis and characterization, Water Resour. Res., 45, W03420, doi:10.1029/2008WR007280, 2009b.

Schmelzbach, C., Tronicke, J., and Dietrich, P.: High-resolution water content estimation from surface-based ground-penetrating radar reflection data by impedance inversion, Water Resour. Res., 48, W08505, doi:10.1029/2012wr011955, 2012.

Schymanski, S. J., Sivapalan, M., Roderick, M. L., Hutley, L. B., and Beringer, J.: An Optimality-Based Model of the Dynamic Feedbacks between Natural Vegetation and the Water Balance, Water Resour. Res., 45, W01412, doi:10.1029/2008wr006841, 2009.
Schymanski, S. J., Kleidon, A., Stieglitz, M., and Narula, J.: Maximum entropy production allows a simple representation of heterogeneity in semiarid ecosystems, Philos. T. Roy. Soc. B, 365, 1449-1455, 2010.

Selker, J. S., Thévenaz, L., Huwald, H., Mallet, A., Luxemburg, W., van de Giesen, N., Stejskal, M., Zeman, J., Westhoff, M., and Parlange, M. B.: Distributed fiber-optic temperature sensing for hydrologic systems, Water Resour. Res., 42, W12202, doi:10.1029/2006wr005326, 2006.

Shannon, C. E.: A mathematical theory of communication, Bell Syst. Tech. J., 27, 623-656, 1948.

Sherman, L. K.: Streamflow from rainfall by the unit graph method, Eng. News-Rec., 108, 501-505, 1932.

Shukla, S., Sheffield, J., Wood, E. F., and Lettenmaier, D. P.: On the sources of global land surface hydrologic predictability, Hydrol. Earth Syst. Sci., 17, 2781-2796, doi:10.5194/hess-17-27812013, 2013.

Sibani, P. and Jensen, H. J.: Stochastic Dynamics of Complex Systems, Imperial College Press, London, UK, 2013.

Singh, R., Wagener, T., van Werkhoven, K., Mann, M. E., and Crane, R.: A trading-space-for-time approach to probabilistic continuous streamflow predictions in a changing climate - accounting for changing watershed behavior, Hydrol. Earth Syst Sci., 15, 3591-3603, doi:10.5194/hess-15-3591-2011, 2011.

Singh, V. P.: The use of entropy in hydrology and water resources, Hydrol. Process., 11, 587-626, 1997.

Singh, V. P. and Rajagopal, A. K.: Some recent advances in application of the principle of maximum entropy (POME) in hydrology, IAHS Publ., 164, 353-364, 1987.

Sivakumar, B.: Chaos theory in hydrology: important issues and interpretations, J. Hydrol., 227, 1-20, 2000.

Sivakumar, B.: Nonlinear dynamics and chaos in hydrologic systems: latest developments and a look forward, Stoch. Environ. Res. Risk A, 23, 1027-1036, doi:10.1007/s00477-008-0265-z, 2009.

Sivapalan, M.: Pattern, Process and Function: Elements of a New Unified Hydrologic Theory at the Catchment Scale, in: Encyclopaedia of Hydrologic Sciences, chapt. 13, vol. 1, Part 1, edited by: Anderson, M. G., John Wiley \& Sons, 193-219, 2005.

Sivapalan, M.: Predictions under Change (PUC): Water, Earth and Biota in the Anthropocene, Research Report, Center for Water as a Complex Ecosystem, University of Illinois at UrbanaChampaign, available at: http://cwaces.geog.uiuc.edu/synthesis/ reports/index.html (last access: 1 July 2013), 2011.

Sivapalan, M., Thompson, S. E., Harman, C. J., Basu, N. B., and Kumar, P.: Water cycle dynamics in a changing environment: improving predictability through synthesis, Water Resour. Res., 47, W00J01, doi:10.1029/2011WR011377, 2011.

Sivapalan, M., Savenije, H. H., and Blöschl, G.: Socio-hydrology: a new science of people and water, Hydrol. Process., 26, 12701276, 2012.

Skøien, J. O., Blöschl, G., and Western, A. W.: Characteristic space scales and timescales in hydrology, Water Resour. Res., 39, 1304, doi:10.1029/2002wr001736, 2003.

Solomonoff, R. J.: A formal theory of inductive inference, Part I, Inform. Control, 7, 1-22, 1964. 
Srinivasan, V., Lambin, E. F., Gorelick, S. M., Thompson, B. H., and Rozelle, S.: The nature and causes of the global water crisis: syndromes from a meta-analysis of coupled human-water studies, Water Resour. Res., 48, W10516, doi:10.1029/2011WR011087, 2012.

Strogatz, S. H.: Nonlinear Dynamics and Chaos: With Applications to Physics, Biology, Chemistry and Engineering, AddisonWesley Publishing Company, Reading, MA, 498 pp., 1994.

Tague, C. and Grant, G. E.: A geological framework for interpreting the low-flow regimes of cascade streams, Willamette River Basin, Oregon, Water Resour. Res., 40, W04303, doi:10.1029/2003WR002629, 2004.

Thompson, S. E., Sivapalan, M., Harman, C. J., Srinivasan, V., Hipsey, M. R., Reed, P., Montanari, A., and Blöschl, G.: Developing predictive insight into changing water systems: useinspired hydrologic science for the Anthropocene, Hydrol. Earth Syst. Sci., 17, 5013-5039, doi:10.5194/hess-17-50132013, 2013.

Troch, P. A., Carrillo, G. A., Heidbüchel, I., Rajagopal, S., Switanek, M., Volkmann, T. H. M., and Yaeger, M.: Dealing with landscape heterogeneity in watershed hydrology: a review of recent progress toward new hydrological theory, Geogr. Compass, 3, 375-392, doi:10.1111/j.1749-8198.2008.00186.x, 2009.

Troch, P. A., Carrillo, G., Sivapalan, M., Wagener, T., and Sawicz, K.: Climate-vegetation-soil interactions and long-term hydrologic partitioning: signatures of catchment co-evolution, Hydrol. Earth Syst. Sci., 17, 2209-2217, doi:10.5194/hess-17-22092013, 2013.

Virgo, N.: From maximum entropy to maximum entropy production: a new approach, Entropy, 12, 107-126, 2010.

Wagener, T., Sivapalan, M., Troch, P., and Woods, R.: Catchment classification and hydrologic similarity, Geogr. Compass, 1, 901931, 2007.

Wagener, T., Sivapalan, M., Troch, P. A., McGlynn, B. L., Harman, C. J., Gupta, H. V., Kumar, P., Rao, P. S. C., Basu, N. B., and Wilson, J. S.: The future of hydrology: An evolving science for a changing world, Water Resour. Res., 46, W05301, doi:10.1029/2009wr008906, 2010.

Wagener, T., Blöschl, G., Goodrich, D. C., Gupta, H. V., Sivapalan, M., Tachikawa, Y., Troch, P. A., and Weiler, M.: A synthesis framework for runoff predictions in ungauged basins, chapt. 2, in: Runoff Predictions in Ungauged Basins, edited by: Blöschl, G., Sivapalan, M., Wagener, T., Viglione, A., and Savenije, H., Cambridge University Press, Cambridge, UK, 2013.

Waldrop, M. M.: Complexity: The Emerging Science at the Edge of Order and Chaos, Viking, London, 1992.

Wang, D. and Wu, L.: Similarity of climate control on base flow and perennial stream density in the Budyko framework, Hydrol. Earth Syst. Sci., 17, 315-324, doi:10.5194/hess-17-315-2013, 2013.
Weijs, S. V., Schoups, G., and van de Giesen, N.: Why hydrological predictions should be evaluated using information theory, Hydrol. Earth Syst. Sci., 14, 2545-2558, doi:10.5194/hess-142545-2010, 2010.

Weijs, S. V., van de Giesen, N., and Parlange, M. B.: Data compression to define information content of hydrological time series, Hydrol. Earth Syst. Sci., 17, 3171-3187, doi:10.5194/hess-173171-2013, 2013a.

Weijs, S. V., van de Giesen, N., and Parlange, M. B.: HydroZIP: how hydrological knowledge can be used to improve compression of hydrological data, Entropy, 15, 1289-1310, doi:10.3390/e15041289, 2013b.

Weinberg, G. M.: An Introduction to General Systems Thinking, John Wiley, Hoboken, N.J., 1975.

Werner, S. and Mörtl, M.: Erstnachweis der FlussKörbchenmuschel (Corbicula fluminea) im Bodensee, Lauterbornia, 49, 93-97, 2004.

Western, A. W., Blöschl, G., and Grayson, R. B.: Toward capturing hydrologically significant connectivity in spatial patterns, Water Resour. Rese., 37, 83-97, doi:10.1029/2000wr900241, 2001.

Westhoff, M. C., Bogaard, T. A., and Savenije, H. H. G.: Quantifying spatial and temporal discharge dynamics of an event in a first order stream, using distributed temperature sensing, Hydrol. Earth Syst. Sci., 15, 1945-1957, doi:10.5194/hess-15-19452011, 2011.

Winsberg, E.: Science in the age of computer simulation, University of Chicago Press, Chicago, USA, 2010.

Yang, D., Kanae, S., Oki, T., Koike, T., and Musiake, K.: Global potential soil erosion with reference to land use and climate changes, Hydrol. Process., 17, 2913-2928, doi:10.1002/hyp.1441, 2003.

Zehe, E. and Blöschl, G.: Predictability of hydrologic response at the plot and catchment scales: role of initial conditions, Water Resour. Res., 40, W10202, doi:10.1029/2003WR002869, 2004.

Zehe, E. and Sivapalan, M.: Threshold behaviour in hydrological systems as (human) geo-ecosystems: manifestations, controls, implications, Hydrol. Earth Syst. Sci., 13, 1273-1297, doi:10.5194/hess-13-1273-2009, 2009.

Zehe, E., Elsenbeer, H., Lindenmaier, F., Schulz, K., and Blöschl, G.: Patterns of predictability in hydrological threshold systems, Water Resour. Res., 43, W07434, doi:10.1029/2006WR005589, 2007.

Zehe, E., Ehret, U., Blume, T., Kleidon, A., Scherer, U., and Westhoff, M.: A thermodynamic approach to link self-organization, preferential flow and rainfall-runoff behaviour, Hydrol. Earth Syst. Sci., 17, 4297-4322, doi:10.5194/hess-17-4297-2013, 2013. 